\title{
Educational Opportunities for Dressage Participants as Perceived by Members of the United States Dressage Federation
}

\author{
Dawn E. Mackenzie
}

Follow this and additional works at: https://researchrepository.wvu.edu/etd

\section{Recommended Citation}

Mackenzie, Dawn E., "Educational Opportunities for Dressage Participants as Perceived by Members of the United States Dressage Federation" (2016). Graduate Theses, Dissertations, and Problem Reports. 6133.

https://researchrepository.wvu.edu/etd/6133

This Thesis is protected by copyright and/or related rights. It has been brought to you by the The Research Repository @ WVU with permission from the rights-holder(s). You are free to use this Thesis in any way that is permitted by the copyright and related rights legislation that applies to your use. For other uses you must obtain permission from the rights-holder(s) directly, unless additional rights are indicated by a Creative Commons license in the record and/ or on the work itself. This Thesis has been accepted for inclusion in WVU Graduate Theses, Dissertations, and Problem Reports collection by an authorized administrator of The Research Repository @ WVU. For more information, please contact researchrepository@mail.wvu.edu. 
Educational Opportunities for Dressage Participants as Perceived by Members of the United States Dressage Federation

\author{
Dawn E. Mackenzie
}

Thesis Submitted to the

Davis College of Agriculture, Natural Resources and Design

At West Virginia University

In Partial Fulfillment of the Requirements

for the Degree of

\author{
Master of Science \\ In \\ Agricultural and Extension Education
}

Harry N. Boone, Jr., Ph.D., Chair

Deborah A. Boone, Ph.D.

Stacy A. Gartin, Ph.D.

School of Design and Community Development

Morgantown, West Virginia

2016

Keywords: Dressage, Education, USDF

Copyright 2016 Dawn E. Mackenzie 


\begin{abstract}
Educational Opportunities for Dressage Participants as Perceived by Members of the United States Dressage Federation
\end{abstract}

Dawn E. Mackenzie

The United States Dressage Federation (USDF) has sought to develop educational support for the American dressage enthusiast since its inception in the 1970s. American riders face unique challenges in comparison to European riders, such as the larger geographic mass of the United States and the logistics of both horse and rider confronting drastically increased travel demands. Additionally, differing educational and financial support infrastructures by country create further obstacles for those industry members who wish to aggressively pursue dressage as either an amateur or professional. While much conjecture and anecdotal evidence to these obstacles are documented by industry professionals, most of this discourse is in the context of success at internationally competitive levels rather than purely educational progress and little of it is supported with academic research.

Within the United States there is very little research addressing the support infrastructure of the American dressage enthusiast. The purpose of this study was to measure the U.S. riders' perceptions of the educational landscape. A random stratified sample of 2015 members of the United States Dressage Federation (USDF) were surveyed in order to ascertain the most prominent perceived obstacles to their success within the industry. Awareness and participation in various educational programming offered specifically by the USDF was also explored. Participants additionally identified sources of educational support they utilized outside of the membership organization. By obtaining demographic information from respondents, the researcher described the current opportunities both nationally and per individual USDF Region. The long-term effects of the study will result in a better understanding of the training options needed to supplement current infrastructure in order to opportunities for American dressage riders. Results are available to regionalized Group Member Organizations to alert them as to both areas of exceptional support and areas where their membership needs assistance. 


\section{DEDICATION}

For Dr. Stephen A. Mackenzie: professor, mentor, debater, catalyst, and father of one very lucky little girl. 


\section{ACKNOWLEDGEMENTS}

Many thanks to the United States Dressage Federation for their cooperation in allowing me to pursue this research, in particular Melissa Schoedlbauer for her endless assistance in being a liaison in a project I dropped in her lap out of the blue.

Additional heartfelt thanks to the faculty and staff of WVU's Davis College, one of the most supportive groups I've yet fallen in with, including my patient committee members. To Dr. Jessica Blythe and Lindsay Willey for their cheerful assistance- I cannot imagine how I would have done this without you.

No thesis would be complete without recognition to fellow graduate students for the endless therapy and comradery; we learned to make panic attacks look good.

To the Devines, who welcomed me into their family of hilarious characters: I'll never be able to thank (or feed) you enough to balance the scales.

Finally: my own incredible family in New York and Boston for the never-ending faith, emotional support, and assistance with logistics that made any of this journey remotely possible, the same way they have made any undertaking conceivable for the duration of my life. 


\section{TABLE OF CONTENTS}

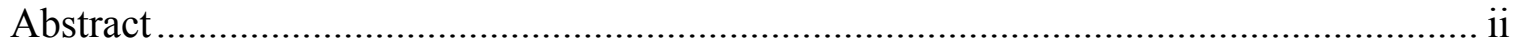

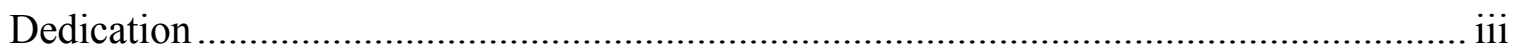

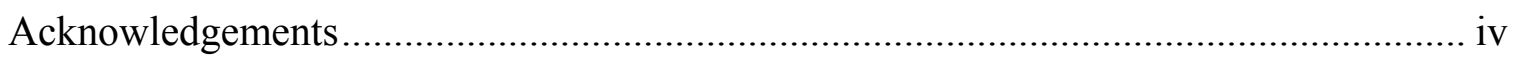

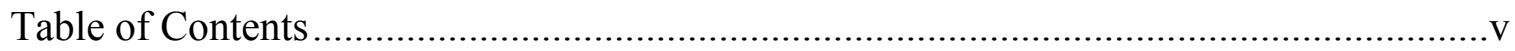

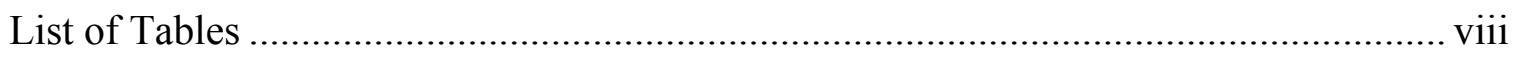

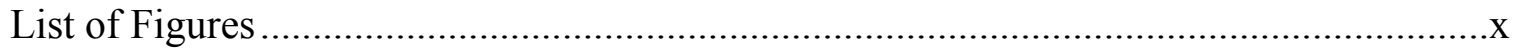

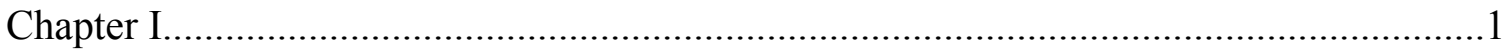

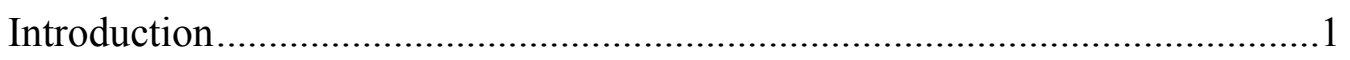

Statement of the Problem....................................................................6

Purpose of the Study ..........................................................................

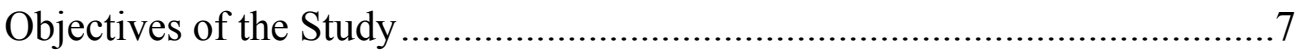

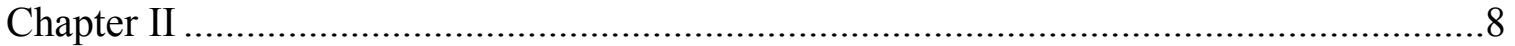

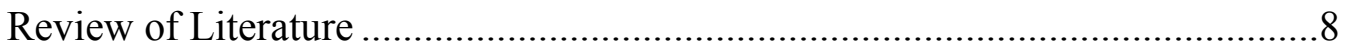

Curriculum Evaluation via the Web Survey ...............................................8

Coaching Programming Available Internationally ................................... 9

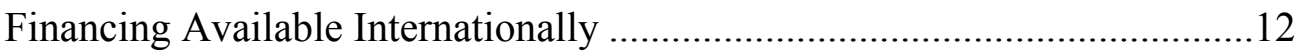

USDF Available Educational Programs ..................................................13

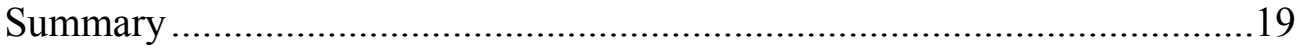

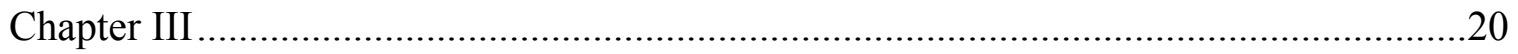

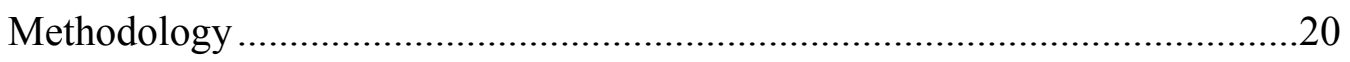

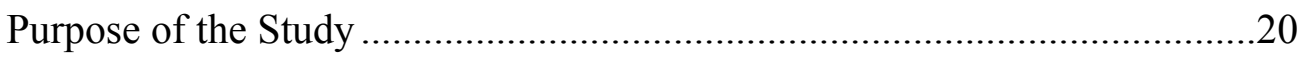

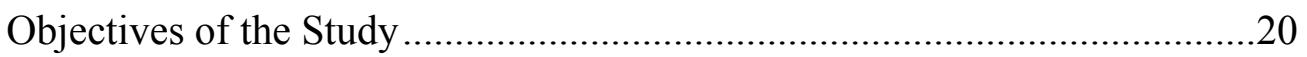

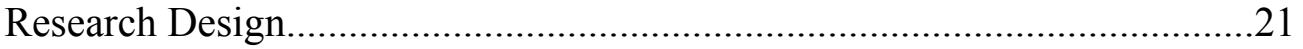

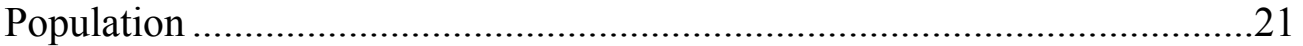

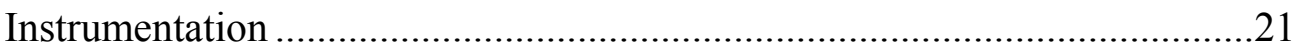

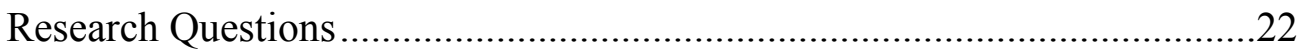

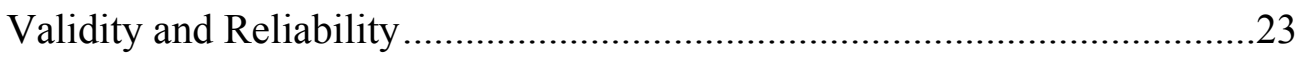

Data Collection Procedures...................................................................24

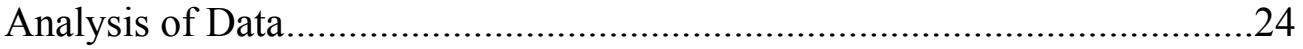

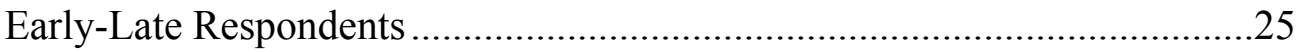

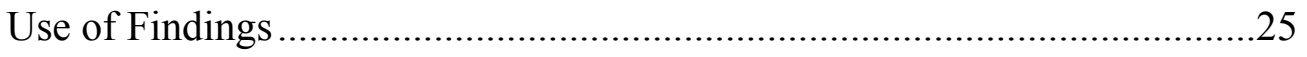




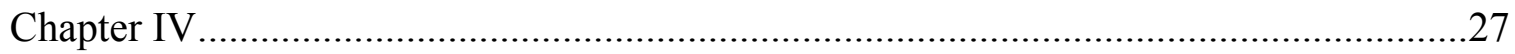

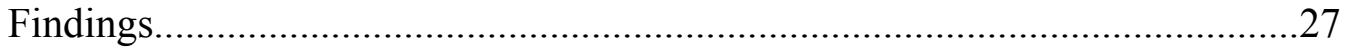

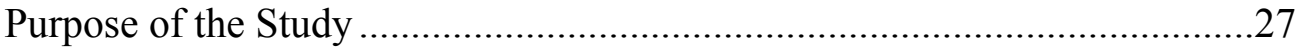

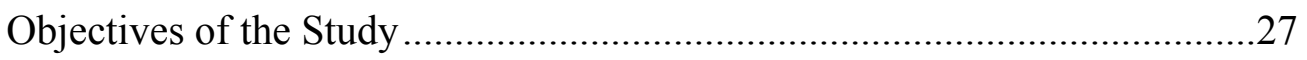

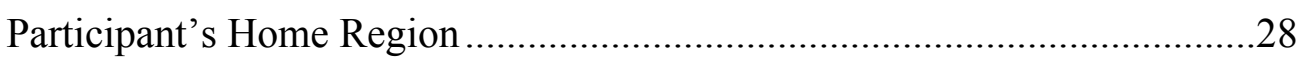

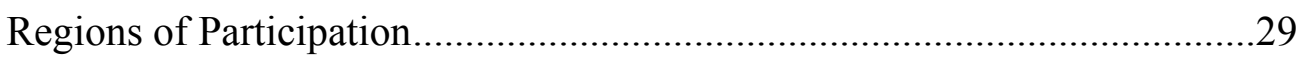

Differences in Regions Lived and Regions Participated ...............................31

Types of USDF Membership ........................................................................

Desired Credentials When Seeking Dressage Instruction ...............................36

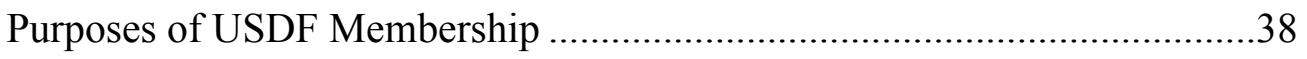

Primary Purpose of USDF Membership .......................................................

Regional Priorities of USDF Membership......................................................40

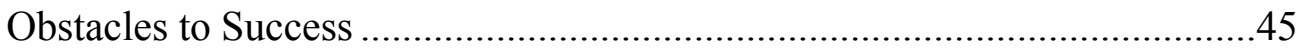

Perceptions of USDF Educational Programs ....................................................49

Perceptions of USDF Educational Resources.................................................57

Frequency of Outside Programming Attended .............................................66

Group Member Organization Use..............................................................67

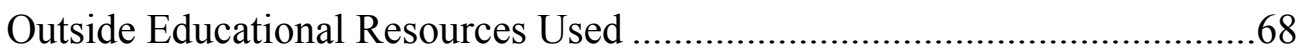

Outside Educational Resources Used Per Region ........................................70

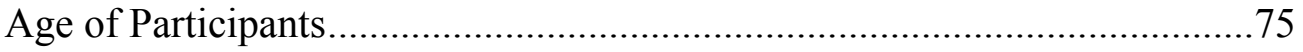

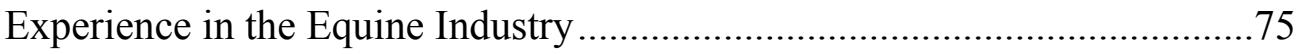

Participants Involvement in Ownership...................................................... 76

Participants Involvement in the Support Industries ........................................77

Participants Involvement with Facilitation of Care .......................................79

Participants' Involvement with Veterinary Decisions .....................................80

Participants Involvement with Farrier-Related Decisions .............................82

Disciplines Membership Has Been Active In ..................................................83

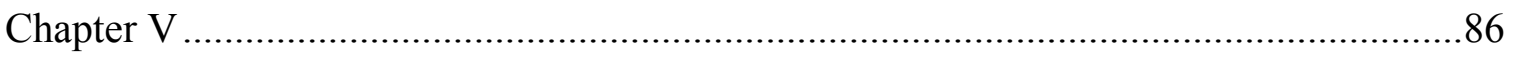

Summary, Conclusions, and Recommendations..............................................86

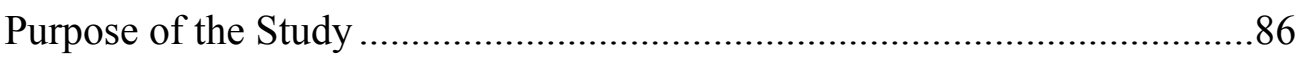

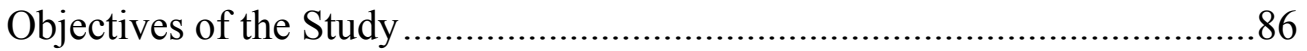

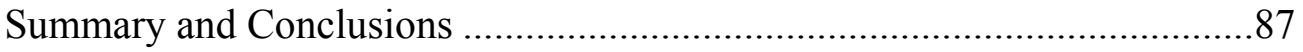

Professional Networking Database .................................................................8 


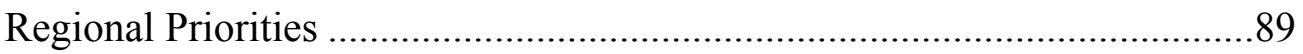

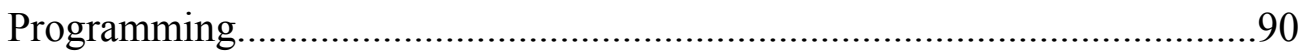

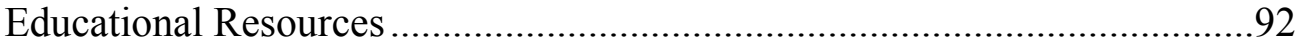

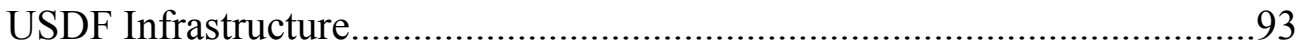

Collaboration with Other Agencies or Sources of Support .............................94

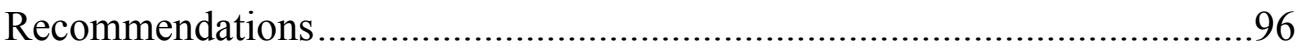

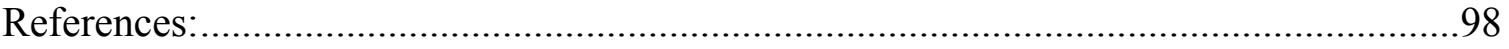

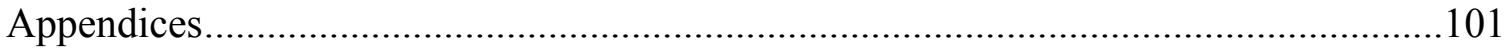

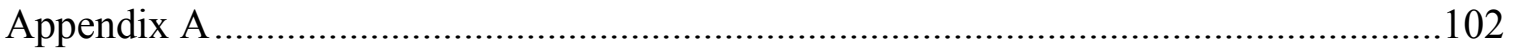

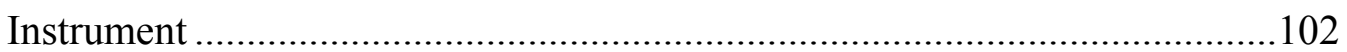

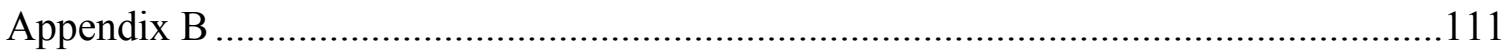

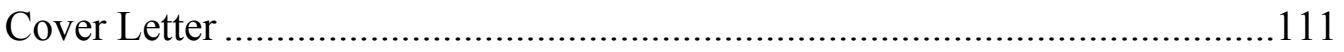

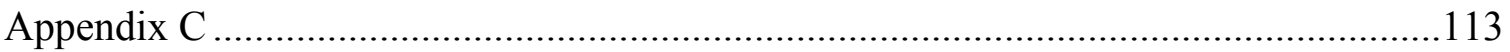

Credentials Sought For Instructors ……………………...............................113

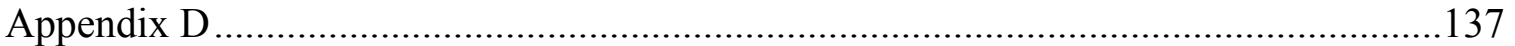

All Possible Purposes of Purchasing USDF Membership ..............................137

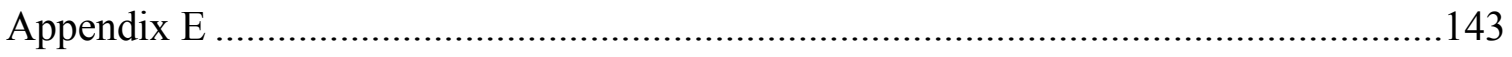

Primary Purpose of Purchasing USDF Membership ......................................143

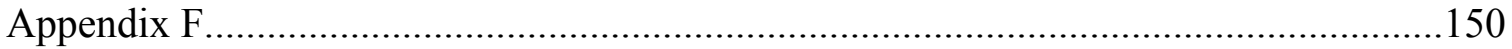

USDF Members' Perceived Obstacles to Success............................................150

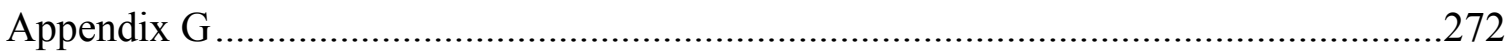

Sources of Outside Educational Support ...................................................272

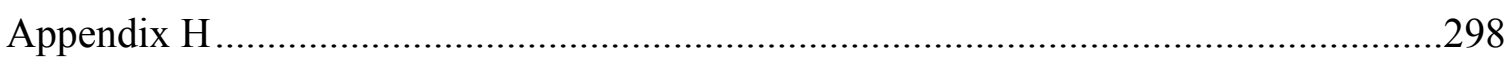

Equine Disciplines Members Are/Have Been Active In ..................................298

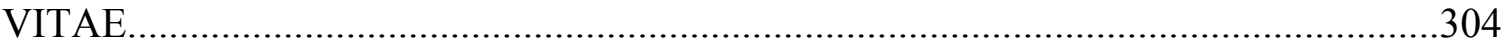




\section{LIST OF TABLES}

$\begin{array}{lll}\text { Table Title } & \text { Page }\end{array}$

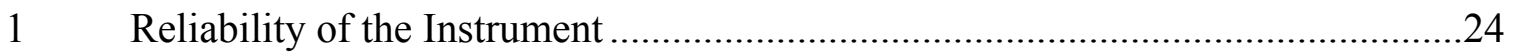

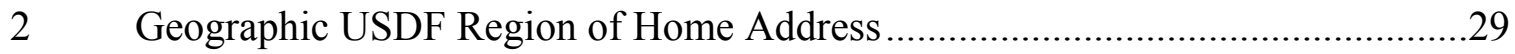

3 USDF Region of Active Participation in USDF Programs N= ...........................31

4 Members' Regions of Active Participation Compared to Home ……………….....33

$5 \quad$ USDF Membership Type Purchased ………………...........................................

6 Credentials Considered Important When Seeking Dressage Instruction.................37

$7 \quad$ All Possible Purposes of Purchasing USDF Membership .......................................39

8 Primary Purpose of Purchasing USDF Membership …………………..............40

9 Reasons for Purchase of USDF Membership by USDF Region.............................43

10 USDF Members Perceived Obstacles to Success $(\mathrm{N}=1420) \ldots \ldots \ldots \ldots \ldots \ldots \ldots \ldots \ldots \ldots \ldots \ldots . . .48$

11 Awareness Levels of USDF Educational Programming.........................................54

12 Participants' Perceptions of Attended USDF Educational Programing ................55

13 Participants' Awareness of USDF Educational Resources......................................63

14 Participants' Perceptions of USDF Educational Resources...................................65

15 Use of Educational Resources/Programming Provided by Sources Outside the

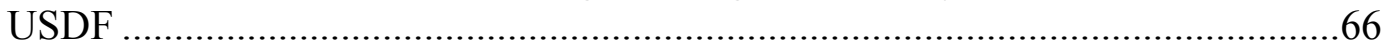

16 Percent Educational Content Outside the USDF Provided by GMOs ...................67

17 Sources of Outside Educational Support $(\mathrm{N}=1481) \ldots \ldots \ldots \ldots \ldots \ldots \ldots \ldots \ldots \ldots \ldots \ldots \ldots \ldots \ldots \ldots . . .70$

18 Sources of Outside Educational Support per Region..............................................73

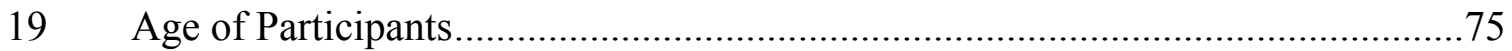

20 Years of Activity Within the Equine Industry ....................................................76

21 Levels of Equine Ownership within USDF Members ( $\mathrm{N}=1587) \ldots \ldots \ldots \ldots \ldots \ldots \ldots \ldots \ldots . . . .77$

22 Involvement with Support Industry: Saddles, Registration, Insurance and Seasonal Showing $(\mathrm{N}=1037)$ 
23 Involvement with Support Industry: Facilitator of Equine Care $(\mathrm{N}=1037) \ldots \ldots \ldots . .80$

24 Involvement with Support Industry: Veterinary Decisions $(\mathrm{N}=1037) \ldots \ldots \ldots \ldots \ldots . . . . .82$

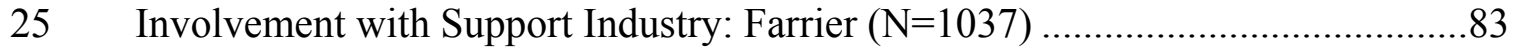

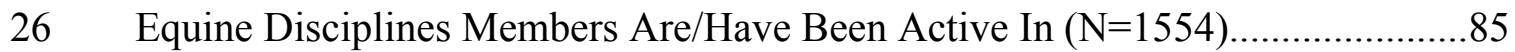

27 Percentage of Members Not Active in Home Region ......................................87

28 Levels of Awareness for Educational Programs ..............................................92

29 Levels of Awareness for Educational Resources............................................93 


\section{LIST OF FIGURES}

Figure Title

Page

1

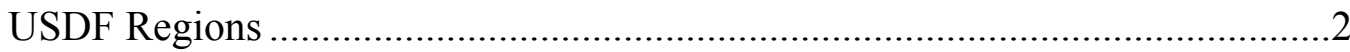




\section{CHAPTER I}

\section{Introduction}

Dressage, one of the longest-established equestrian disciplines (Morgan, 2006), has had formalized educational facilities firmly established in European countries for hundreds of years (Spanische Hofreitschule, n.d.), the most prominent being the Royal Academy of Equestrian Art, founded in 1420 in Portugal, and the Spanish Riding School in Vienna, founded in 1572 (Bryant, 2006). Additional facilities include the École Nationale d'Équitation, established in France during the late 1500s, and the Royal Andalusian School of Equestrian Art in Spain. While the latter was officially founded in 1973, the facility formalized equine exhibitions in that area dating back to the 1600 s (Bryant, 2006). While European dressage enthusiasts have access to hundreds of years of established dressage curriculum, the United States was not even a recognized country until after many of these schools were established.

The United States' relatively short history contributes to the country presenting a much different landscape for its dressage industry (Gribbons, 2012a). From the country’s origin in 1776 until 1948, the primary training structure for the United States' equestrian sports was controlled through the scaffolding provided by the military (Bryant, 2006). In 1948 the traditional cavalry's dissolution and mechanization changed the focus of the sport to the country's citizenry - with no formalized structure to the educational development of the industry. While the lack of military dominance allowed many more possibilities for successful civilian competitors, the United States lacked a formalized support structure within the industry (United States Dressage Federation, n.d.d). When interviewed regarding her experience in the 1960 Olympic Games, United States 
Dressage Federation Hall of Famer Jessica Ransehousen is quoted as saying "[t]he whole feeling in those days was that if you happened to make the team, you were on your own" (Bryant, 2008, p. 169).

To address the general disorganization of a discipline he was passionate for, Lowell Boomer initiated a meeting in 1973 of a group of citizens with an "[interest] in the advancement of dressage," resulting in the formation of the United States Dressage Federation, or USDF. Since this meeting, the USDF has operated with the mission of supporting "the dedication to education, recognition of achievement, and promotion of dressage.” Today, the USDF is a nonprofit organization acting as the single national membership organization serving United States dressage enthusiasts (United States Dressage Federation, n.d.e).

While the USDF operates on a national level, the organization splits the United States into nine geographic regions (see Figure 1) which may contain any number of affiliate organizations (around 130) known as Group Membership Organizations (GMOs), in order to better facilitate meeting the goals of its various members (United States Dressage Federation, n.d.c). Because of this structure, opportunities available to

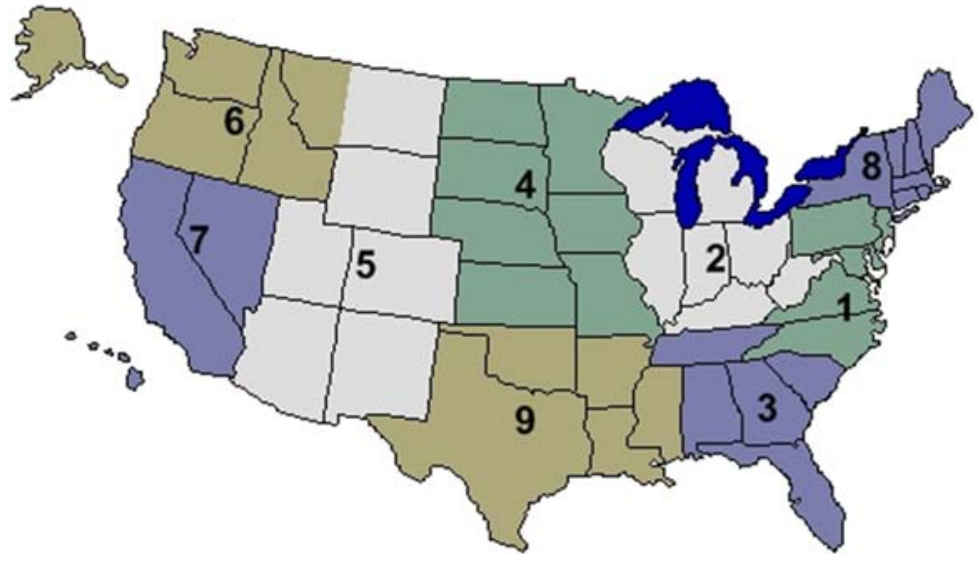

Figure 1: USDF Regions (United States Dressage Federation, n.d.1)
USDF members are not

consistent across the entire membership.

\section{Different types of} memberships are available, allowing for varying levels of access to different member 
perks, such as discounts at popular equestrian retailers, other online educational sources, or various insurance or competitive opportunities. While Participating Memberships are geared towards active competitors, there are also Business Memberships for industry networking, Youth Participating Memberships for members under 21 who are also active competitors, and Education Memberships for those whose main focus is not competition. The last option, Group Memberships, allow members of the regionally available GMOs to also be members of the USDF itself (United States Dressage Federation, n.d.m). This permits group members to have access to the various activities and support available to their own local club, as well as the support of the national infrastructure. The available USDF educational programming currently administered via both the centralized USDF organization, as well as regionally through various affiliate Group Member Organizations (United States Dressage Federation, n.d.b), is coordinated nationally by the USDF Regional Directors (United States Dressage Federation, n.d.k).

Other outside, locally available organizations, such as Cooperative Extension, 4-H, Pony Club, breed associations or veterinary clinics may also offer educational programming that is either dressage-specific or relevant. So many different possible alternatives make it very difficult to maintain an accurate accounting for the educational options available to the USDF's various members at any given time, though the option does exist for outside sources to register their own events under the USDF via their "USDF University" program (United States Dressage Federation, n.d.j).

The structure of the sport is such that competitions are also a largely educational activity, wherein the rider will receive back judges' evaluations and suggestions on the movements they performed in competition. Individual competitive rides are referred to as 
"tests", and to progress to the next level scores higher than $65 \%$ must be achieved. In this way, it can be very difficult to draw a line between the purely educational and purely competitive aspects of the discipline. It can also be difficult to remember to make this distinction within the USDF as well. Identified as an educational organization, the USDF is still heavily involved in the competitive aspect of the sport, as membership is required for rated competition (unless the entrant wishes to pay higher entry fees) and grants roughly 2,000 awards for competitive achievement annually (United States Dressage Federation, n.d.a). There are also USDF Competition Programs, held separately from the United States Equestrian Federation (USEF), which oversees all other rated dressage shows (United States Dressage Federation, 2015, p. 48).

These details reveal that competition is a very relevant part of the education of the dressage rider, and this brings its own challenges as well. The cost of showing can be fairly prohibitive, and if there is extensive travel to be done to reach locations of shows or educational programs, the logistics are speculated to become prohibitive. The simple geographic mass of the United States in comparison to many smaller countries mandates a greater amount of travel to reach educational events which exist for European dressage enthusiasts in a much higher density. Travel itself is not an issue facing only competitors hoping to qualify for educational programming, but a factor every competitor must tackle, as ex-Olympic coach Anne Gribbons addresses in an article for the Chronicle of the Horse. She states that the "vast separation between our riders and our shows is one of our greatest stumbling blocks" (Gribbons, 2012c, We Need to Practice at Shows, para. 6). Difficulties arise for many competitors when one factors in not only the cost of travel for potential students, but the stressors placed upon the team needing to acclimate 
to a new environment. Horses can easily become prone to colic (the leading cause of equine death) by disruptions in daily routine, diet, or added stress, all of which occur during travel (U.C. Davis School of Veterinary Medicine, 2008). The intensity of disruption to the horse increases as the travelling distances increase.

Anne Gribbons, the United States Dressage Olympic Team Coach through 2012, has long been writing articles addressing the lack of quality horses available for the American rider as well. She believes that the emphasis in the United States relies too heavily on importing what is available abroad and the industry's potential talent suffers for that fact. She also indicates having fewer high-quality horses than high-quality developing riders in the United States is problematic (Gribbons, 2012d). It is Gribbons' opinion that the United States can front an acceptable amount of quality riders, but the number of quality horses available to these riders is significantly less. She would prefer each have a few at their disposal (a standard situation in Europe) in order to accelerate a higher level of learning (Gribbons, 2012a). The American dressage environment has historically relied upon the habit of travelling to European countries to import horses ranging from unbroken babies as possible prospects to horses already competing at the desired international levels. This is hardly considered a sustainable practice, as the cost of these animals is beyond what most amateur developing riders can put forward and one must still consider the cost of importing these purchased animals; neither does this practice seek to strengthen the American industry on an international scale and the highly competitive Europeans will not be placing their best stock for sale to foreign countries. Americans are still left grasping at the second-best offerings, hoping to remain competitive against the bloodstock held back from the U.S. buyers (Gribbons, 2012b). 
There are many acknowledged challenges for the American dressage enthusiast, and while the industry has a uniquely intertwined relationship with its competitive and educational aspects, the USDF seeks to present educational programming that will advance its members towards their goals in both competition and industry standards.

\section{Statement of the Problem}

While these various problems have been discussion points for industry professionals over the years, little research in the United States is available identifying the actual memberships' views on these topics. This information will be useful in assisting the administration in ensuring the USDF's educational missions match those of their membership or categorizing the other educational opportunities available locally for collaboration. Research on the impact of programming could be utilized to identify areas of success as well as needed improvement within existing programming, and will provide feedback as to potential future programming.

\section{Purpose of the Study}

The purpose of this study was threefold: to identify educational opportunities available to current USDF members outside of the organization to assist them in reaching their goals, both regionally as well as nationally; to evaluate current USDF-offered programming; and to identify the top perceived obstacles toward members achieving their goals in the industry. Once this information can be ascertained, appropriate changes can be made to a variety of programs to assist with strengthening the education available to our developing rider population. With this understanding, new educational curriculum can both become more effective and address any previously unknown obstacles on a national or regional basis. 


\section{Objectives of the Study}

The objectives of the study were reflected in the following research questions:

1. What Regions were USDF members involved in educational activities?

2. What was the participants' level of involvement in both the equine and dressage industries?

3. What were the USDF members' goals with their USDF membership?

4. What were the three most significant perceived obstacles to achieving their goals for the membership?

5. What was the level of awareness of available USDF educational programming?

6. What were the USDF members' evaluations of USDF programming they have utilized?

7. What resources outside of the USDF have members used for their education in dressage? 


\section{CHAPTER II}

\section{Review of Literature}

\section{Curriculum Evaluation via the Web Survey}

Gilbert and Trudel (1999) stressed the importance of non-traditional evaluative measures for coaching effectiveness in particular, stating that the context of each participants' involvement needs to be considered to make the evaluation pertinent. Web surveys have been found to be more economically efficient with more flexibility of purpose when compared to some of the more traditional methods such as mailings, interviews, or telephoning (Wholey, Hatry \& Newcomer, 2010). Proper formatting of both questions and visual cues are vital for the online survey, as increased error messages were shown to increase the likelihood of the respondent cancelling the entire response (Christian, Dillman \& Smyth, 2007). Surveys are also shown to return more accurate results when the time is spent to ask multiple questions to separate categories within constructs, rather than providing instructions to the respondent (Redline, 2013). Christian, Dillman and Smyth reported that changing the wording of the questions to be answered did not confuse respondents, provided that instructions are included in the areas of response (Christian et al., 2007). This study also revealed the importance of the formatting of questions utilizing abbreviations or date format, as the respondents were more likely to adopt the questions' formatting for their responses (Christian et al., 2007).

In a similar study prior to Christian's 2005 study, while testing a population aged $18-25$, the same authors also found that when comparing online surveys to telephone surveys, the population contacted via the telephone were much more likely to offer an extremely positive ranking on a 5- or 11-category scale than those contacted via an online 
survey, face-to-face, or mailing surveys (Christian, Dillman \& Smyth, 2005). The authors hypothesized that the lack of visual reminders for the possible response choices paired with the faster pace set by the interviewer, rather than the respondent, may be contributing factors in this particular phenomenon (Christian et al., 2005). Verbal reiterations of the scale numbers and their representative positive/negative connotations prior to every question was not seen as a sufficient reminder to address this issue (Christian et al., 2005). When scalar- format methods were utilized, this study also discovered that respondents provided with a visual definition of all possible choice points were less likely to have validity issues that those surveys with only polar choice points identified (Christian et al., 2005).

Cleo Redline published findings on the importance of defining the categorical concepts of the given survey to the respondent. For instance, many respondents asked on a quantity of owned shoes did not exclude sneakers until instructed to (Redline, 2013).

A Michigan State University reported successful evaluation in as early as 1994 by surveying programming participants directly (Hammerschmidt, Murphy, Youatt, Sawyer \& Andrews, 1994). Carefully constructing questions addressing understanding of the material, the amount of new information learned, and they excitement and enjoyment they got from participating in the various activities (Hammerschmidt et al., 1994). The resulting information assisted programmers in initiating successful changes in the available curriculum (Hammerschmidt et al., 1994).

\section{Coaching Programming Available Internationally}

A study published in Romania focusing on youth athletics highlighted the variations in the global coaching infrastructure resulting from various international, 
continental, and nationalized sporting organizations (Al-Busafi, Ramadan \& Kilani, 2012). Laid out are the many different options for various countries: adapting other countries' coaching standards as their own, requiring no standards whatsoever, adopting a continental program such as the European structure, or developing their own continental program such as in Africa (Al-Busafi et al., 2012). The European Coaching Council has gone so far as to develop a project to coordinate the continent's coaching to network regarding current issues, research within the industry, and communication between professionals (Robinson, 2010).

The German sporting infrastructure is heavily subsidized and run through the Federal Ministry of the Interior and has 27 million members in 89,000 sporting clubs. This organization organizes mentorships for its aspiring coaches, as well as internationallevel higher education courses twice a year, lasting five months in duration (Robinson, 2010). France maintains a National Institute of PE and Sport, a centralized location where all top athletes and coaching staff are trained, in addition to the support system provided by the Ministry of Youth and Sports at the lower levels.

In The Netherlands, nearly one third of the entire population (6 million members) are involved in a sporting organization overseen by their Olympic Committee, who initializes educational programming with guidance from the various individualized sporting organizations (Robinson, 2010). The United States lacks even this formal a coaching structure, as it may have different requirements and expectations dependent upon the federated state, without even taking into account the various coaching regiments dependent upon the particular sport in question once one moves beyond the simple traditional physical education environment (Al-Busafi et al., 2012). This varies 
drastically with the highly standardized levels of curriculum available to proponents of the International Association of Athletic Federations, which offers specialized curriculum materials, lecturers and guidelines for each of its 5 levels (Al-Busafi, et al. 2012). Also available in many nations is the option through this standardized coaching structure to specialize in a particular sport through a national sporting organization or a governmental agency, providing a standardization of general practices and knowledge to all coaches regardless of their specialty (Al-Busafi et al., 2012). New Zealand, Ireland, Singapore, Hong Kong, Australia and Hungary were all compared in the 2012 Romanian study, with results showing variations that had worked successfully (Al-Busafi et al., 2012).

New Zealand and Singapore both maintain a coaching curriculum managed at the national level with three levels of achievement, consisting of courses with academic support at each level for each individual sport in that country, but Singapore includes a two-step process to each level, consisting of the theoretical aspects and the technical application (Al-Busafi et al., 2012). Hong Kong follows exactly the same format, but with an additional four parts to each of the three levels, addressing Sports Science (phycology, physiology, fitness, talent, motor control and biomechanics), Sports Coaching (planning, practice and adapted sports), Coaches Management (legalities and management practices), and Sports Medicine (drug regulations, injury and rehabilitation) (Al-Busafi et al., 2012).

Ireland and Hungary both offer a four-level program run with structured building curriculum at each level for each sport, but while Ireland's programs are regulated at the national level. Hungary's programs are operated through the higher educational 
institutions and can take the longest at one to three years for each level (Al-Busafi et al., 2012).

A 1975 report by the Australian Sports Institute indicated that the current (at the time) apprentice-based training of coaches needed to be abandoned for a more formalized curriculum (Robinson, 2014), but still utilizes a much more non-traditional format with each of the participating 70 national sporting organization dictating the number of levels to their accreditation and the methods of instruction (Al-Busafi et al., 2012). Another report in 2010 indicated further adaptations were needed in the areas of additional training opportunities and financial support (Robinson, 2014).

The Romanian study surmised that assessing coaching effectiveness was one of the biggest problems they could reveal, and recognized the severe lack of research in this area to date (Al-Busafi et al., 2012). Another related study completed in 1999 was one of the few to attempt to evaluate such programming on such a large scale, but returned no concrete results since the purpose of the study was to evaluate the method's application, rather than any actual evaluation of learned information (Gilbert \& Trudel, 1999).

\section{Financing Available Internationally}

In 2004, the Japanese women's field hockey team nearly had to withdraw from the Athens Olympic Games due to a lack of corporate funding despite being considered top contenders for a medal. It is not uncommon in Japan for corporations to employ top athletes within their company so that the entire team is owned, sponsored and marketed by that particular company. Businesses can take advantage of the networking their international competitors are capable of while in the spotlight, as well as that athlete's continued loyalty and employment after athletic retirement (Sawano, 2010). While this 
may seem antiquated from an American point of view, the practice is actually seen in a number of Asian countries like China, Korea and Japan, as well as Scandinavian countries. The German sports team Leverkusen, founded in 1904, is a still-existing team from the corporate era, though the practice did not achieve the same foothold there as in other countries. The United States' earliest baseball teams were formed in this way as well, but labor and union laws eventually disbanded the practice domestically (Sawano, 2010). In Japan, the relaxation of the definition of an amateur athlete with the 1984 Olympics led to the increase of corporate athletes who could compete at Olympic international levels.

\section{USDF Available Educational Programs}

There are fifteen educational programs offered through the USDF as listed in their 2015 Member Guide (United States Dressage Federation, 2015). Twelve are expanded upon for the purpose of the literature review; as per the USDF, the Musical Freestyle, Pas De Deux, and Quadrille are all listed as educational programs, though for the purposes of this study these programs are excluded due to their similarity to a competitive class.

The first is listed as the Hart Program (Horse and Rider Together), which is an online tool used for individuals to log their riding time on an unlimited number of horses, earning achievements as they go. The log may be shared over social media, and may be a record of progress for teams as well (United States Dressage Federation, 2015).

The second program is listed as the USDF Instructor/Trainer Program geared towards providing workshops on various topics, as well as certifications through the 
USDF at various levels of proficiency: Training through First Level; Second Level; Third through Fourth Level; FEI A; FEI B (United States Dressage Federation, 2015).

The third program is the "L" Education Program, which strives to develop understanding in trainers, instructors, competitors and spectators with regard to how performance is judged from Training through Second Level competition. This is also used as a forum for potential candidates wishing to apply for the USEF ' $r$ ' Judge Training Program to be evaluated, and as a continuing education platform for current "L" judges. The program is taught by "USDF approved, USEF-licensed "S" judges" (United States Dressage Federation, 2015) and is formatted into two sections. The first section is constructed as 'A Judges Perspective', which is considered the foundation for the remainder of the program and is open to all USDF members. The second section is for selection of candidates looking to obtain or extend their judging credentials (United States Dressage Federation, 2015).

The Continuing Education in Dressage Judging is the fourth listed program and is developed on a regional basis by the USDF Judges Committee with the goal of serving both USDF "L" Program participants and graduates, as well as allowing for auditors. Funding for these programs are provided through the Dressage Foundation's Edgar Hotz Judges' Fund, and are organized by the individual regions' Group Member Organization or other approved organization (United States Dressage Federation, 2015).

Continuing education for trainers and instructors are addressed through the Succeed/USDF FEI- Level Trainers Conference. In this fifth program, presenters from various aspects of the profession are contracted to explore teaching techniques (United States Dressage Federation, 2015). 
The USDF Annual Convention sponsored by Adequan is also listed as the sixth educational program by the USDF. This event is a platform to conduct the business of the organization, as well as allowing for member networking and educational programming focused towards all levels of dressage participants (United States Dressage Federation, 2015).

The seventh program, the USDF Sport Horse Prospect Development Forum, is a platform provided by the show Dressage at Devon, held in Devon Pennsylvania once yearly. This program's mission is “to bridge the current educational gap related to the training of sport horse prospects as they progress from in-hand to under-saddle, and eventual competition" (United States Dressage Federation, 2015, p. 16).

The USDF Sport Horse Seminar, the eighth program, is a series of two days of education addressing qualities desired in a sport horse and how to rate them. These educational opportunities are focused towards breeders, riders, trainers, and potential owners. Attendance at these seminars are also required of USEF- licensed dressage sport horse breeding judges (United States Dressage Federation, 2015).

USDF Sport Horse Handlers Clinics, the ninth program, seeks to educate their audience regarding the proper preparation and rules of showing horses in the in-hand classes (United States Dressage Federation, 2015).

The tenth program, the USDF Adult Clinic Series sponsored by Nutrena, seeks to provide an easily affordable population of high-quality clinicians to the general membership. Eight horse and rider teams are selected to demonstrate for the clinicians, and there is also a lecture portion of the program (United States Dressage Federation, 2015). 
The USDF Junior/Young Rider Clinic Series, sponsored by Platinum Performance and with additional funding from The Dressage Foundation, is the eleventh program which targets the younger rider teams for educational opportunities. This would include pony riders aged 12 to 14 , and riders aged 14 to 21 "to become part of the USEF pipeline" (United States Dressage Federation, 2015). High-profile instructors are provided and again eight rider teams are selected to demonstrate for the clinician. Theory sessions will be included and auditors of all ages are welcome to the programs (United States Dressage Federation, 2015).

Lastly, the USDF University is a program allowing for any members seeking to continue their education on any variety of topics. Credit towards certificates and diplomas may be earned by physically attending programs or taking a variety of listed online classes/courses as well. Organizers of various programs (online courses, lectures, seminars, workshops, symposiums, etc.) looking to be accredited through the program are provided with an application process and credits may be accumulated through the program over an unlimited amount of time.

In addition to these educational programs listed in the USDF Member's Guide, there are eleven educational resources available through the USDF. The USDF produces the weekly USDF Official Podcast, available for mobile download or on their website. When accessed on 25 Feb 2016, the site showed 114 episodes available and 80,710 total downloads (United States Dressage Federation, 2016b).

The USDF also sponsors a program called eTRAK, which is a login-based online educational aggregate site. Members can access information through categories such as In-Depth Studies, Quick Studies, Targeted Studies, and Features. Much like a regular 
new aggregate, suggestions on content to read can be made to the members based on their previous viewing history and the page links to other educational programming initiatives within the USDF such as the H.A.R.T. program and Podcasts (United States Dressage Federation, 2016b).

Within eTRAK, members and non-members alike can find the PDF file United States Dressage Federation Glossary of Judging Terms (United States Dressage Federation, 2016a). This is a collection of terminology for universal understanding of what the judges seek to communicate to competitors on their score cards. For example, if a judge were to award a low score on a 20 meter circle, and then simply note "overbent" as their comment, the document would expand upon that comment, allowing the competitor to know the judge was referring to "excessive lateral displacement of the neck relative to the horse's body, occurring in the neck itself or at the base of the neck, causing lack of apparent uniformity of the lateral curve of the "bent" horse" (United States Dressage Federation, 2014, p. 7). The entry goes on to specify that in other countries, the term can be used to indicate "excessive longitudinal flexion at the poll" (United States Dressage Federation, 2014, p. 7).

The USDF runs social media accounts on Facebook, Twitter, Flickr, and YouTube. The Facebook page promotes links to the original USDF website, educational resources and opportunities, as well as notices of office closures and created events of Regional events of USDF-sponsored events. It is followed by 41,014 people, with 54 reviews rating it an overall 4.5/5 stars (United States Dressage Federation, n.d.h). The USDF's Twitter account is followed by 9,555 users, has posted 2,122 tweets since June of 2009, and includes retweets from various USDF events nation-wide from followers. 
The mission statement is prominently displayed, along with links to the USDF website (United States Dressage Federation, n.d.i). USDF's Flickr page (created in 2013) displays 1,898 pictures from various USDF sponsored events, and has 29 followers (United States Dressage Federation, n.d.f). USDF's YouTube channel holds 110 videos uploaded from January of 2008 to January 2016 of various educational clips and events. The channel has 2,249 subscribers (United States Dressage Federation, n.d.n).

USDF Connection is a monthly periodical generated by the USDF, and is available to members through a mailed print version as well as online PDFs. Online versions contain links to video clips and other related content, while both versions contain educational articles, industry news and even essays from industry professionals (United States Dressage Federation, n.d.g).

The USDF is responsible for a number of publications available through their online webstore (USDF Online Store, n.d.). USDF Show Biz is a reference for the successful execution of a competitive dressage event, USDF recognized or otherwise, and is available for $\$ 15.95$. The USDF Lungeing Manual is available for $\$ 12.00$ as a supplemental resource primarily for the USDF Instructor/Trainer Program and instructs the reader in the theory and application of lungeing in relation to the horse and rider (USDF Online Store, n.d.). The USDF Teaching Manual is also supplemental for the USDF Instructor/Trainer Program, and provides teaching topics as discussed in the workshops, and a reference for applying the theory of teaching philosophies and materials for the reader. It is available for $\$ 30.00$. The United States Dressage Federation Guide to Dressage is written by Jennifer Bryant and seeks to explain the industry to a reader who is assumed to have no practical knowledge of the dressage world at all. It 
includes an industry history, competitive information, riding instruction, information on applications within other disciplines, management of the horse, and rider fitness issues. It is available through the webstore for $\$ 35.00$. On the Levels: $D V D$ is available for $\$ 29.95$ and provides the viewer with recorded competitive tests with narrations from international trainers, coaches and Olympians. The 2015 edition features the tests that will be in effect until November of 2018 (USDF Online Store, n.d.). On the Levels is also offered through an online subscription, where subscribers can have access to an online video library of the same content, at a price of $\$ 19.95$ annually (On the Levels, n.d.).

\section{Summary}

The United States offers unique challenges to its dressage enthusiasts in regard to educational programming, equine development, geographic mass, and financial obstacles. While there is much written by industry professionals and anecdotal evidence to substantiate these issues, there is very little actual academic research addressing the challenges. 


\section{CHAPTER III}

\section{Methodology}

\section{Purpose of the Study}

The purpose of this study was threefold: to identify educational opportunities available to current USDF members to assist them in reaching their goals within the organization, both regionally as well as nationally; to evaluate current USDF-offered programming; and to identify the top perceived handicaps toward members' goals in the industry. Once this information can be ascertained, appropriate changes can be made to a variety of programs to assist with strengthening the education available to our developing rider curriculum can both become more effective and address any previously unknown obstacles on a national or regional basis.

\section{Objectives of the Study}

The objectives of the study were reflected in the following research questions:

1. What Regions were USDF members involved in educational activities?

2. What was the participants' level of involvement in both the equine and dressage industries?

3. What were the USDF members' goals with their USDF membership?

4. What were the three most significant perceived obstacles to achieving their goals for the membership?

5. What was the level of awareness of available USDF educational programming?

6. What were the USDF members' evaluations of USDF programming they have utilized? 
7. What resources outside of the USDF have members used for their education in dressage?

\section{Research Design}

The study utilized a descriptive research techniques in the form of an online survey generated through Qualtrics ${ }^{\circledR}$. The survey was accessed via an individual link emailed to each member. Descriptive statistics "enable researchers to organize, summarize, and describe observations" (Ary, Jacobs, Razavieh and Sorensen, 2006, p. 117). This information will assist in providing stakeholders with knowledge of what members of the United States Dressage Federation identify as sources of support, opinions of educational programming, and obstacles to success.

\section{Population}

The target population consists of all USDF members except than those holding Business Memberships. This membership bracket was excluded due to its concentration of the retail and business aspect of the industry, rather than geared towards those actively involved in educational aspects. The USDF maintains over 95 percent of their membership's email addresses. As a result the accessible population consisted of all nonbusiness USDF members with email addresses available through the USDF. A stratified random sample of each USDF Region was compiled with a total 8,784 email addresses. Upon completion of the study a total of 1,872 members responded, giving the study a $21.31 \%$ response rate.

\section{Instrumentation}

A survey was developed with both Likert-type questions addressing program awareness and evaluation and open ended questions addressing perceived obstacles. 
Various multiple choice options allow for respondent text input as well. The survey was implemented through the servers and software at Qualtrics ${ }^{\circledR}$ and was accessed by the respondent through a specific link for each competitor. These identifiers were not included in data exported from Qualtrics ${ }^{\circledR}$ for analysis.

The majority of the questions involved in evaluating programming utilized Likerttype scales, although obstacles were left open-ended for the respondent to enter. The constructs flowed in the following order: membership goals and obstacles; USDF program awareness and evaluation; USDF-generated resource awareness and evaluation; available outside opportunities; demographics.

Procedures were taken to avoid the five common errors in descriptive research. Sampling and frame errors were avoided by selecting a stratified random sample (by region) from the entire population. Selection error was avoided by using the official list provided by the USDF. The use of a valid and reliable instrument insured that measurement error was not an issue. Efforts to avoid non-response error are addressed later in the chapter.

\section{Research Questions}

The first construct allowed respondents to identify aspects regarding individual goals and obstacles within the USDF membership, like identification of the USDF Region of residence, as well as the Region(s) in which members participated in programming. This construct also identified priority certifications awarded to potential dressage trainers or instructors, as perceived by the membership, both within the USDF and externally. 
The second construct addressed the respondent's awareness and experience with individual programs offered by the USDF. Individuals who had attended programming also had the opportunity to indicate the program's level of impact.

The third construct addressed the respondents' awareness and experience in regards to the use of USDF-generated educational resources, such as texts, podcasts or social media. The level of impact was also ascertained.

The fourth construct identified the outside sources of educational dressage opportunities that the respondents considered available to them. Demographic information included members' ages and generalized involvement in the equine industry. Equestrian-related demographics identified a basis of owner involvement with their horses and their lifestyle on a daily basis.

\section{Validity and Reliability}

The instrument was presented to a panel of experts consisting of teacher educators and equine specialists at West Virginia University to establish content and face validity. The instrument was deemed to have content and face validity.

Split-half reliability procedures were used to establish reliability of the instrument. Data from the final data set were used in the procedures. A SpearmanBrown coefficient was calculated for five constructs with the instrument (see Table 1). All five constructs exhibited "exemplary" reliability (Robinson, Shaver, \& Wrightsman, 1991): regions (q1 \& q2) (Spearman- Brown $=.733)$, reasons for joining USDF (q3\&4) (Spearman- Brown =.309), outcomes of USDF membership (q5) (Spearman- Brown $=.366$ ), participation in USDF (q8) (Spearman- Brown $=.786$ ), USDF educational 
activities $(\mathrm{q} 10)($ Spearman- Brown $=.716)$, and equine activities $(\mathrm{q} 22)$ (Spearman- Brown $=.681)$.

Table 1

Reliability of the Instrument

\begin{tabular}{lcc}
\hline Construct & $\begin{array}{c}\text { Spearman Brown } \\
\text { Coefficient }\end{array}$ & Reliability \\
\hline Regions (q1 \& q2) & .733 & Exemplary \\
Reasons for Joining USDF (q3\&4) & .309 & Exemplary \\
Outcomes of USDF membership (q5) & .366 & Exemplary \\
Participation in USDF (q8) & .786 & Exemplary \\
USDF Educational Activities (q10) & .716 & Exemplary \\
Equine activities (q22) & .681 & Exemplary
\end{tabular}

\section{Data Collection Procedures}

Emails containing the cover letter (see Appendix B) and link to the Qualtricsgenerated survey (see Appendix A) were mailed December 3, 2015. A follow-up email letter was sent with the link to non-respondents on December 21, 2015 and again on January 62016 (see Appendix B). The last responses were recorded on January 19, 2016 prior to the survey being closed.

\section{Analysis of Data}

Due to the instrument being a mixed methods survey, a qualitative analysis of open-ended responses addressing perceived obstacles to success within the industry was conducted, as well as quantitative analysis to analyze other constructs. Quantitative data were analyzed utilizing the SPSS 23.0 for Windows. The level of significance was set $a$ 
priori at $\alpha \leq 0.05$ for all statistical tests. Descriptive analyses appropriate for the respective scales of measurement were performed on the data including measures of central tendency (mean, median, or mode) and variability (frequencies or standard deviation). The results were represented as frequencies and percentages as well as mean, median and mode in both table and narrative form. Data were broken down into individual USDF Regions when the researcher deemed warranted.

\section{Early-Late Respondents}

The group of respondents were divided into two groups based on the time of their response. Individuals who responded to the survey on or before the original deadline were considered as "early respondents." Individuals who completed the survey after the initial deadline were considered as "late respondents." Because late respondents are most like non-respondents (Miller \& Smith, 1983) the analysis provided an estimate of nonresponse error. A chi-square statistical procedure was used to compare early and late respondents on "years active in the equine industry," "attendance at USDF adult clinics," and "USDF home region." Statistical differences were found in one of the three comparisons, therefore, all generalizations from this study were limited to the individuals who completed the survey.

\section{Use of Findings}

There are a variety of institutions that would benefit from the findings of this study. These findings will be used by the United States Dressage Federation to adapt the currently developing infrastructure to address members' concerns. Results will be broken into other demographics to compare the individual regions' perceived strengths and areas of improvement, or to see if there are trends in any other demographics that could be 
addressed by the organization early on. Additionally, the study will identify local sources of support for the discipline that the USDF may be able to collaborate with in order to provide additional programming. Youth organizations such as 4-H or junior divisions of any breed or discipline may adapt their programs to address parallel issues as well and further studies could be adapted from the findings in regards to various issues brought to light via local breakdown of data. 


\section{CHAPTER IV}

\section{Findings}

\section{Purpose of the Study}

The purpose of this study was threefold: to identify educational opportunities available to current USDF members to assist them in reaching their goals within the organization, both regionally as well as nationally; to evaluate current USDF-offered programming; and to identify the top perceived handicaps toward members' goals in the industry. Once this information can be ascertained, appropriate changes can be made to a variety of programs to assist with strengthening the education available to our developing rider curriculum can both become more effective and address any previously unknown obstacles on a national or regional basis.

\section{Objectives of the Study}

The objectives of the study were reflected in the following research questions:

1. What Regions were USDF members involved in educational activities?

2. What was the participants' level of involvement in both the equine and dressage industries?

3. What were the USDF members' goals with their USDF membership?

4. What were the three most significant perceived obstacles to achieving their goals for the membership?

5. What was the level of awareness of available USDF educational programming?

6. What were the USDF members' evaluations of USDF programming they have utilized? 
7. What resources outside of the USDF have members used for their education in dressage?

\section{Participant's Home Region}

Participants were asked to indicate their home USDF region (see Figure 1). A total of 1,866 people selected the USDF region that represented their home address, with results showing a relatively even number of participants from all domestic regions. Two hundred and six individuals (11.04\%) identified Region 1, which includes Pennsylvania, New Jersey, Delaware, North Carolina, Washington DC, and the West Virginia counties of Morgan, Berkeley and Jefferson. Two hundred and twenty-six individuals (12.11\%) identified Region 2, which encompasses Wisconsin, Michigan, Illinois, Indiana, Kentucky, Ohio, and all other West Virginian counties. One hundred and ninety-four individuals (10.40\%) selected Region 3 as their home (Tennessee, Alabama, Georgia, Florida and South Carolina). The most represented Region was 4 with 233 individuals $(12.49 \%)$ responding from North Dakota, South Dakota, Nebraska, Kansas, Minnesota, Iowa and Missouri. The least represented Region was 5, with 192 individuals (10.29\%) identifying from eastern Montana, Wyoming, Utah, Colorado, Arizona, New Mexico or western Texas. Region 6 was selected by 213 respondents (11.41\%), representing Alaska, Washington, Oregon, Idaho, and western Montana. Two hundred and six respondents (11.04\%) selected Region 7, encompassing California, Nevada and Hawaii. One hundred and ninety-four participants $(10.40 \%)$ indicated their home as Region 8: Maine, New Hampshire, Vermont, New York, Massachusetts, Rhode Island and Connecticut. Region 9, including eastern Texas, Oklahoma, Arkansas, Louisiana, and Mississippi, was selected by 201 participants (10.77\%). One individual (0.05\%) selected Region 10, 
representing a home address outside of the United States (see Table 2). See Figure 1 for a map of USDF Regions.

Table 2

Geographic USDF Region of Home Address

\begin{tabular}{lcc}
\hline & $\mathrm{N}$ & $\%$ \\
\hline Region 1 & 206 & 11.04 \\
Region 2 & 226 & 12.11 \\
Region 3 & 194 & 10.40 \\
Region 4 & 233 & 12.49 \\
Region 5 & 192 & 10.29 \\
Region 6 & 213 & 11.41 \\
Region 7 & 206 & 11.04 \\
Region 8 & 194 & 10.40 \\
Region 9 & 201 & 10.77 \\
Region 10 & 1 & 0.05 \\
Total & 1866 & 100.00 \\
\hline
\end{tabular}

\section{Regions of Participation}

A total of 1,866 members answered the question asking which USDF Regions they attended programming or events within, generating a total of 2267 responses. Two hundred and fifty-two participants (13.4\%) indicated they were active in Region 1, which includes Pennsylvania, New Jersey, Delaware, North Carolina, Washington DC, and the West Virginia counties of Morgan, Berkeley and Jefferson. Three hundred and two individuals (16.13\%) indicated they were active in Region 2, which encompasses 
Wisconsin, Michigan, Illinois, Indiana, Kentucky, Ohio, and all other West Virginian counties. Two hundred and sixty-five individuals (14.16\%) indicated they were active in Region 3, including Tennessee, Alabama, Georgia, Florida and South Carolina. Two hundred and sixty-one participants (13.94 \%) indicated they were active in Region 4, representing North Dakota, South Dakota, Nebraska, Kansas, Minnesota, Iowa and Missouri. One hundred and ninety-six (10.47\%) of the participants selected Region 5 as an area of participation, representing eastern Montana, Wyoming, Utah, Colorado, Arizona, New Mexico or western Texas. Region 6, including Alaska, Washington, Oregon, Idaho, and western Montana was selected by 222 individuals (11.86 \%). Two hundred and forty-eight members (13.25\%) indicated they were active in Region 7 , including California, Nevada and Hawaii. Two hundred and four individuals (10.90 \%) indicated they were active in Region 8 (Maine, New Hampshire, Vermont, New York, Massachusetts, Rhode Island and Connecticut) and 210 participants (11.22 \%) identified with Region 9 (eastern Texas, Oklahoma, Arkansas, Louisiana, and Mississippi). Four individuals $(0.21 \%)$ indicated activity on an international level (Region 10), and 103 participants $(5.50 \%)$ selected not being active participants in any USDF programming or events (see Table 3). See Figure 1 for a map of USDF Regions. 
Table 3

USDF Region of Active Participation in USDF Programs

\begin{tabular}{lcc}
\hline & $\mathrm{N}$ & $\%$ \\
\hline Region 1 & 252 & 13.46 \\
Region 2 & 302 & 16.13 \\
Region 3 & 265 & 14.16 \\
Region 4 & 261 & 13.94 \\
Region 5 & 196 & 10.47 \\
Region 6 & 222 & 11.86 \\
Region 7 & 248 & 13.25 \\
Region 8 & 204 & 10.90 \\
Region 9 & 210 & 11.22 \\
Region 10 & 4 & 0.21 \\
Do not participate & 103 & 5.50 \\
Total & 2267 & \\
\hline
\end{tabular}

\section{Differences in Regions Lived and Regions Participated}

The data were examined to determine the differences for USDF members between the Regions they reside and the Regions they participated (see Figure 1). Region 1 respondents indicated that 76.59 percent of members living there actually participated in Region 1, with 6.37 percent participating in Region 8, and 6.79 percent in Region 3. Other regional participation included Region 2 (4.3\%). Less than one percent of members living in Region 1 were active in Region 4. 
Region 2 respondents indicated that 69.54 percent of members living there participated in Region 2, with 10.34 percent participating in Region 4, 8.30 percent in Region 3 and 3.97 percent in Region 1. Less than two percent of members participated elsewhere.

Region 3 saw activity from 66.06 percent of the members living there, while 9.52 percent participated in Region 1, 6.79 percent participated in Region 1, 6.95 percent participated in Region 2, and 2.45 percent participated in Region 8. Region 3 members were also active in Region 7 (4.42\%), with less than two percent active elsewhere.

Region 4 retained the participation of 84.29 percent of its members, while 15.56 percent participated in Region 2. Members were also active in Region 9 (8.10\%), Region $3(3.02 \%)$, and Region 4 (2.04\%). Less than two percent participated in other Regions.

Region 5 had the highest percentage of its members participating in the home region, with 91.84 percent of its members participating. Members were active in both Regions 7 (6.85\%), Region 6 (6.76\%), and Region 8 (2.45\%). Region 9 saw participation from 2.38 percent of Region 5 participants, and less than two percent participated in other Regions.

Region 6 retained 90.64 percent of its membership's activity. Other Regional participation included 8.47 percent of members participating in Region 7, 2.04 percent in Region 5, and less than two percent of members participating in other Regions.

Region 7 had 79.44 percent of membership participating in the home region. Other participation included 2.25 percent active in Region 6, and less than two percent in any other Region. 
Table 4

Members' Regions of Active Participation Compared to Home

\begin{tabular}{|c|c|c|c|c|c|c|c|c|c|c|c|}
\hline \multicolumn{12}{|c|}{ Regions Participated } \\
\hline & & & Region 1 & Region 2 & Region 3 & Region 4 & Region 5 & Region 6 & Region 7 & Region 8 & Region 9 \\
\hline \multirow{12}{*}{ 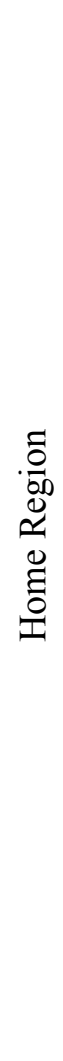 } & \multirow{2}{*}{ Region 1} & $\mathrm{f}$ & 193 & 13 & 18 & 2 & 0 & 0 & 0 & 13 & 0 \\
\hline & & $\%$ & 76.59 & 4.30 & 6.79 & 0.77 & 0.00 & 0.00 & 0.00 & 6.37 & 0.00 \\
\hline & \multirow{2}{*}{ Region 2} & $\mathrm{f}$ & 10 & 210 & 22 & 27 & 1 & 1 & 2 & 4 & 2 \\
\hline & & $\%$ & 3.97 & 69.54 & 8.30 & 10.34 & 0.51 & 0.45 & 0.81 & 1.96 & 0.95 \\
\hline & \multirow{2}{*}{ Region 3} & $\mathrm{f}$ & 24 & 21 & 175 & 3 & 0 & 0 & 6 & 5 & 1 \\
\hline & & $\%$ & 9.52 & 6.95 & 66.04 & 1.15 & 0.00 & 0.00 & 2.42 & 2.45 & 0.48 \\
\hline & \multirow{2}{*}{ Region 4} & $\mathrm{f}$ & 2 & 47 & 8 & 220 & 4 & 0 & 1 & 1 & 17 \\
\hline & & $\%$ & 0.79 & 15.56 & 3.02 & 84.29 & 2.04 & 0.00 & 0.40 & 0.49 & 8.10 \\
\hline & \multirow{2}{*}{ Region 5} & $\mathrm{f}$ & 1 & 1 & 2 & 1 & 180 & 15 & 17 & 5 & 5 \\
\hline & & $\%$ & 0.40 & 0.33 & 0.75 & 0.38 & 91.84 & 6.76 & 6.85 & 2.45 & 2.38 \\
\hline & \multirow{2}{*}{ Region 6} & $\mathrm{f}$ & 0 & 1 & 2 & 1 & 4 & 201 & 21 & 0 & 1 \\
\hline & & $\%$ & .00 & 0.33 & 0.75 & 0.38 & 2.04 & 90.54 & 8.47 & 0.00 & 0.48 \\
\hline
\end{tabular}


Table 4 (continued)

Members' Regions of Active Participation Compared to Home

\begin{tabular}{|c|c|c|c|c|c|c|c|c|c|c|c|}
\hline \multicolumn{12}{|c|}{ Regions Participated } \\
\hline & & & Region 1 & Region 2 & Region 3 & Region 4 & Region 5 & Region 6 & Region 7 & Region 8 & Region 9 \\
\hline \multirow{6}{*}{ 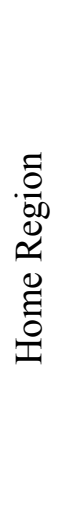 } & \multirow{2}{*}{ Region 7} & $\mathrm{f}$ & 2 & 2 & 4 & 2 & 3 & 5 & 197 & 1 & 1 \\
\hline & & $\%$ & 0.79 & 0.66 & 1.51 & 0.77 & 1.53 & 2.25 & 79.44 & 0.49 & 0.48 \\
\hline & \multirow{2}{*}{ Region 8} & $\mathrm{f}$ & 20 & 4 & 16 & 0 & 1 & 0 & 1 & 175 & 1 \\
\hline & & $\%$ & 7.94 & 1.32 & 6.04 & 0.00 & .51 & 0.00 & 0.40 & 85.78 & 0.48 \\
\hline & \multirow{2}{*}{ Region 9} & $\mathrm{f}$ & 0 & 3 & 18 & 5 & 2 & 0 & 2 & 0 & 182 \\
\hline & & $\%$ & 0.00 & 0.99 & 6.79 & 1.92 & 1.02 & 0.00 & 0.81 & 0.00 & 86.67 \\
\hline
\end{tabular}


Region 8 included the activity of 85.78 percent of its membership. Other regional participation included 7.94 percent active in Region 1, 6.04 percent active in Region 3 and less than two percent of members living in Region 8 were active in any other region. Activities in Region 9 included 86.67 percent of its members active in the home region. Other participation included 6.79 percent active in Region 3, and less than two percent active elsewhere. Region 10 was excluded from this analysis in the interest of keeping the member's identity confidential (see Table 4). See Figure 1 for a map of USDF Regions.

\section{Types of USDF Membership}

A total of 1,804 individuals entered 2,047 responses to a query regarding which type of membership each participant had purchased. One thousand two hundred and seventy-five respondents (68.11\%) purchased a Participating Membership, while 645 (34.46 \%) had membership with the USDF through a Group Membership. One hundred and twenty individuals (6.41\%) had a Youth Participating Membership and seven respondents ( $0.37 \%)$ had an Educational Membership. Sixty-two participants, representing 3.31 percent of respondents, indicated they did not know which type of membership they had obtained (see Table 5). 
Table 5

USDF Membership Type Purchased

\begin{tabular}{lcc}
\hline & $\mathrm{N}$ & $\%$ \\
\hline Participating Membership & 1275 & 68.11 \\
Group Membership & 645 & 34.46 \\
Youth Participating Membership & 120 & 6.41 \\
Education Membership & 7 & 0.37 \\
I don't know & 62 & 3.31 \\
Total & 2109 & 100.00 \\
\hline
\end{tabular}

\section{Desired Credentials When Seeking Dressage Instruction}

When asked what credentials members valued when seeking dressage instruction, 1,795 individuals offered 4,315 selections of valued credentials. The majority of participants $(\mathrm{N}=1408 ; 75.21 \%)$ stated they valued personal recommendations. Nine hundred and seventy-four respondents $(52.03 \%)$ valued a potential instructor's USDF medals, while 793 participants (42.36\%) valued a USDF Certified Instructors rating. One hundred and forty-nine individuals (7.96\%) selected USEA Instructor Certification Program credentials and $85(4.54 \%)$ selected American Riding Instructor Certification as a valued credential. Seventy-nine individuals (4.22\%) selected a collegiate degree as important and 43 (2.30 \%) selected Certified Horseman's Association Certification. Thirty-two participants (1.71\%) selected the United States Hunter Jumper Associations Trainer Certification Program credentials as a valued credential (see Table 6).

Respondents were given the opportunity to identify "other" credentials members valued when seeking dressage instruction. One hundred and seventy-six individuals 
referenced competitive successes as a valued gauge of a potential instructor (see Table 6) and 140 respondents specifically stated the member would do their own personal research or observations to determine for themselves. Ninety text participants cited a need to discover a potential instructors teaching methodology or communication style as vital for a potential instructor as well. Thirty-two individuals specified discovering whom the individual in question had trained with or under and 26 respondents cited logistics such as price and distance to a potential instructor.

Table 6

Credentials Considered Important When Seeking Dressage Instruction

\begin{tabular}{lcc}
\hline & $\mathrm{N}$ & $\%$ \\
\hline Personal recommendations & 1408 & 75.21 \\
USDF medals (Bronze, Silver, Gold) & 974 & 52.03 \\
USDF Certified Instructors & 793 & 42.36 \\
United States Eventing Association Instructor & 149 & 7.96 \\
Certification Program credentials & 85 & 4.54 \\
American Riding Instructor Certification & 79 & 4.22 \\
Collegiate degree & 43 & 2.30 \\
Certified Horseman's Association Certification & 32 & 1.71 \\
United States Hunter Jumper Associations & 614 & 32.80 \\
Trainer Certification Program credentials & 138 & 7.37 \\
Other (please list) & 4315 & \\
Other (please list) & & \\
Total & & \\
\hline
\end{tabular}


Of the 92 respondents specifically mentioning another certification, license, or credential they would seek beyond those available as a multiple choice, 29 stated they sought instruction from a USDF or FEI level judge. Eighteen stated they sought competitors of the international caliber and 13 stated they sought information from Centerline specifically. British Horse Society, American Association for Horsemanship Safety, Centered Riding Instructor and German Bereiter/Reitlehrer certifications were also mentioned (see Appendix C).

\section{Purposes of USDF Membership}

When asked to identify all possible purposes which USDF members intended to utilize their memberships, 1,142 respondents $(63.98 \%)$ indicated education with the purpose of training the horse, while 1,125 respondents (63.03\%) indicating advancement in competition as a purpose as well. One thousand and eighty-five members (60.78\%) selected education with the purpose of training the rider and 616 individuals (34.51\%) selected keeping up with industry trends and news as another purpose. Five hundred and thirty-two participants (29.80\%) valued the membership perks and discounts provided, while 357 (20\%) selected certifications. Three hundred and fourteen individuals (17.59 $\%)$ indicated value towards education for dressage judging and 209 (11.71\%) selected equine breed promotion (see Table 6). One hundred and fifty-nine individuals (8.91\%) selected "other," which were categorized into four sections. Eighty-four of these individuals listed a reason relating to showing or competition, 22 identified educational purposes, 21 indicated networking, and 17 stated that USDF membership was either a requirement of their riding club or due to their membership in a GMO (see Table 7; Appendix D). 
Table 7

All Possible Purposes of Purchasing USDF Membership

\begin{tabular}{lcc}
\hline & $\mathrm{N}$ & $\%$ \\
\hline Equine breed promotion & 209 & 11.16 \\
Advancement in competition & 1125 & 60.10 \\
Certifications & 357 & 19.07 \\
Education for dressage judging & 314 & 16.77 \\
Education for training of the horse & 1142 & 61.00 \\
Education for instruction of the rider & 1085 & 57.96 \\
Industry trends-news & 616 & 32.91 \\
Member perks-discounts & 532 & 28.42 \\
Other & 159 & 8.49 \\
Total & 5539 & \\
\hline
\end{tabular}

\section{Primary Purpose of USDF Membership}

When 1,793 total respondents were asked to identify the one primary purpose of their USDF membership, 867 (48.35\%) selected advancement in competition. Two hundred and eighty-three participants (15.78\%) selected education for instruction of the rider and 247 (13.78\%) selected education for training of the horse. One hundred and eighty-one individuals (1.09 \%) entered a selection of "other," and their responses were included in Appendix E. Sixty-seven members (3.74\%) selected industry trends and news, $44(2.45 \%)$ selected certifications, and $40(2.23 \%)$ selected member perks and discounts as a primary purpose of membership. Thirty-eight members (2.12\%) selected 
education for dressage judging and $26(1.45 \%)$ selected equine breed promotion (see Table 8).

Of the 181 members who selected "other," 97 members stated a reason related to competition and showing. Thirty-two entered statements relating to simply wanting to support an industry they wanted to stay involved with (many citing old age as keeping them from having another reason), 15 mentioned requirements of their GMO, and 14 stated educationally-related reasons (see Appendix E).

Table 8

Primary Purpose of Purchasing USDF Membership

\begin{tabular}{lcc}
\hline & $\mathrm{N}$ & $\%$ \\
\hline Advancement in competition & 867 & 48.35 \\
Education for instruction of the rider & 283 & 15.78 \\
Education for training the horse & 247 & 13.78 \\
Industry trends-news & 67 & 3.74 \\
Certifications & 44 & 2.45 \\
Member perks-discounts & 40 & 2.23 \\
Education for dressage judging & 38 & 2.12 \\
Equine breed promotion & 26 & 1.45 \\
Other & 181 & 10.09 \\
Total & 1793 & 100.00 \\
\hline
\end{tabular}

\section{Regional Priorities of USDF Membership}

The selected purposes for USDF membership were then divided up to reflect priorities per individual USDF Region. The priority for USDF membership within 
Region 1 was "advancement in competition," $(\mathrm{N}=128 ; 53.56 \%)$. The second highest priority was "education for training of the horse" $(\mathrm{N}=37 ; 15.48 \%)$ and third was "education for instruction of the rider" $(\mathrm{N}=33 ; 13.81 \%)$. "Other" was selected by 15 respondents (6.28\%).

Region 2's selected priority was also "advancement in competition" $(\mathrm{N}=158$; $53.38 \%$ ) and 35 members (11.82 \%) selected "education for instruction of the rider." Thirty members (10.14\%) chose both "education for training the horse" and "other." Thirteen members (4.39\%) selected "industry trends/news" and nine members (3.04 \%) chose "education for dressage judging." All other options were chosen by less than three percent of the participants.

In Region 3 “advancement in competition" was chosen by 124 members $(49.40$ $\%)$ and 42 members (16.73\%) chose "education for training the horse." Twenty-six members (10.36 \%) chose "other," 25 selected "education for instruction of the rider," (9.96\%) and 13 chose "education for dressage judging" (5.18\%). "Industry trends/news" was selected by nine respondents ( $3.59 \%$ ), and all other categories were selected by less than three percent of the participants.

Region 4's participants selected "advancement in competition" as the main priority by 130 individuals (51.59\%) and 44 (17.46\%) selected "education for instruction of the rider" as their priority. Another $28(11.11 \%)$ selected "education for the training of the horse" as their priority, $22(8.73 \%)$ selected "other," and nine (3.57\%) selected "certifications." All other reasons were selected by less than three percent of participants.

In Region 5 the majority of 85 individuals (44.50\%) selected "advancement in competition" as the primary reason for membership, with $34(17.80 \%)$ selecting 
"education for training of the horse." Thirty-two members (16.75\%) selected "education for instruction of the rider" as their reason, 17 (8.90\%) chose "other," and nine (4.71\%) chose "industry trends/news." Eight members (4.19\%) selected "education for dressage judging" and other categories were chosen less than three percent of the time.

Region 6's participant majority also chose "advancement in competition" with 53.05 percent $(\mathrm{N}=113)$ and 13.62 percent $(\mathrm{N}=29)$ chose "education for instruction of the rider." Twenty-seven members (12.68 \%) chose "other," 9.86 percent $(\mathrm{N}=21)$ selected "education for training of the horse" and all other categories were selected by less than three percent of the Region's participants.

Region 7 had 127 (53.36\%) of the participants select "advancement in competition" and 29 (12.18\%) selected "education for instruction of the rider." Twentyfive members (10.5\%) chose "education for training the rider," $10(4.20 \%)$ selected both "certifications" and "industry news/trends," and eight (3.36\%) selected "education for dressage judging." The other possible reasons for USDF membership were chosen by less than three percent of participants.

Region 8's majority also selected "advancement in competition" as the primary reason for membership by 87 members (43.94\%), and 33 (16.67\%) selected "education for training the horse." Thirty-one participants (15.66\%) chose "education for instruction of the rider," 21 (10.61\%) selected "other," and nine (4.55\%) chose "education for dressage judging." Six members (3.03\%) chose both "certifications" and "member perks/discounts" as their priority and the other selections were selected by less than three percent of the participants. 
Table 9

Reasons for Purchase of USDF Membership by USDF Region

\begin{tabular}{|c|c|c|c|c|c|c|c|c|c|c|}
\hline & & \multicolumn{9}{|c|}{ Home Region } \\
\hline & & Region 1 & Region 2 & Region 3 & Region 4 & Region 5 & Region 6 & Region 7 & Region 8 & Region 9 \\
\hline \multirow{2}{*}{$\begin{array}{l}\text { Equine breed } \\
\text { promotion }\end{array}$} & $\mathrm{f}$ & 4 & 8 & 1 & 4 & 1 & 1 & 4 & 1 & 3 \\
\hline & $\%$ & 1.67 & 2.70 & 0.40 & 1.59 & 0.52 & 0.47 & 1.68 & 0.51 & 1.45 \\
\hline \multirow{2}{*}{$\begin{array}{l}\text { Advancement } \\
\text { in competition }\end{array}$} & $\mathrm{f}$ & 128 & 158 & 124 & 130 & 85 & 113 & 127 & 87 & 107 \\
\hline & $\%$ & 53.56 & 53.38 & 49.40 & 51.59 & 44.50 & 53.05 & 53.36 & 43.94 & 51.69 \\
\hline \multirow[t]{2}{*}{ Certifications } & $\mathrm{f}$ & 5 & 8 & 5 & 9 & 3 & 5 & 10 & 6 & 3 \\
\hline & $\%$ & 2.09 & 2.70 & 1.99 & 3.57 & 1.57 & 2.35 & 4.20 & 3.03 & 1.45 \\
\hline \multirow{2}{*}{$\begin{array}{l}\text { Education for } \\
\text { dressage } \\
\text { judging }\end{array}$} & $\mathrm{f}$ & 8 & 9 & 13 & 5 & 8 & 6 & 8 & 9 & 6 \\
\hline & $\%$ & 3.35 & 3.04 & 5.18 & 1.98 & 4.19 & 2.82 & 3.36 & 4.55 & 2.90 \\
\hline \multirow{2}{*}{$\begin{array}{l}\text { Education for } \\
\text { training the } \\
\text { horse }\end{array}$} & $\mathrm{f}$ & 37 & 30 & 42 & 28 & 34 & 21 & 25 & 33 & 28 \\
\hline & $\%$ & 15.48 & 10.14 & 16.73 & 11.11 & 17.80 & 9.86 & 10.50 & 16.67 & 13.53 \\
\hline \multirow{2}{*}{$\begin{array}{l}\text { Education for } \\
\text { instruction of } \\
\text { the rider }\end{array}$} & $\mathrm{f}$ & 33 & 35 & 25 & 44 & 32 & 29 & 29 & 31 & 32 \\
\hline & $\%$ & 13.81 & 11.82 & 9.96 & 17.46 & 16.75 & 13.62 & 12.18 & 15.66 & 15.46 \\
\hline
\end{tabular}


Table 9 (continued)

Reasons for Purchase of USDF Membership by USDF Region

\begin{tabular}{lccccccccccc}
\hline & & \multicolumn{1}{c}{ Home Region } \\
\cline { 3 - 10 } & & Region 1 & Region 2 & Region 3 & Region 4 & Region 5 & Region 6 & Region 7 & Region 8 & Region 9 \\
\hline $\begin{array}{l}\text { Industry } \\
\text { trends-news }\end{array}$ & $\mathrm{f}$ & 6 & 13 & 9 & 6 & 9 & 5 & 10 & 4 & 6 \\
& $\%$ & 2.51 & 4.39 & 3.59 & 2.38 & 4.71 & 2.35 & 4.20 & 2.02 & 2.90 \\
\hline $\begin{array}{l}\text { Member } \\
\text { perks- } \\
\text { discounts }\end{array}$ & $\mathrm{f}$ & 3 & 5 & 6 & 4 & 2 & 6 & 5 & 6 & 6 \\
\hline \begin{tabular}{l} 
Other \\
\hline
\end{tabular} & $\mathrm{f}$ & 15 & 30 & 26 & 2.39 & 1.59 & 1.05 & 2.82 & 2.10 & 3.03 & 2.90 \\
\hline
\end{tabular}


Region 9 also chose "advancement in competition" as the first priority $(51.69 \%$, $\mathrm{N}=107)$, with 32 individuals (15.46\%) choosing "education for instruction of the rider," and $28(13.53 \%)$ selecting "education for training of the horse." Sixteen members (7.73 $\%$ ) selected "other," with the other categories receiving less than three percent of selections by participants (see Table 9).

\section{Obstacles to Success}

Members were asked to list via text entry their three biggest obstacles to success. One thousand four hundred and twenty members entered a total of 3,682 statements which were then categorized into topics (see Table 10). Financial difficulties were mentioned in 936 statements, including the following sample of quotes (see Appendix F):

- "Affording membership in both the USDF and USEF"

- "Cost - being able to afford to attend enough shows to receive USDF awards"

- "Educational opportunities/fulfillment of requirements for judging, certification etc. are not available locally. Too expensive and time consuming to travel."

- "Financial cost to obtain "r" Judge licensing" Educational or programming challenges were cited in 855 statements, including the following sample of quotes (see Appendix F):

- "Would like more opportunities to ride in amateur oriented clinics."

- "Training the horse and myself at the same time. Fortunately I have excellent help."

- "Improving USDF instructor education and certification"

- "Availability of good instruction that is near enough to me that I can take frequent lessons." 
Competition-related challenges were mentioned in 749 statements, including the following sample of quotes (see Appendix F):

- "Receiving my Gold Medal"

- "What judges want example [individual] doing western dressage is just the exact same profile and contact she rides always just in western saddle, western horses use more leg seat than contact so who knows what they really want. Stock horses can't compete because of bias already and now they can't even pin western"

- "Not enough local competition"

- "competing against "amateurs" who have more time and opportunities (such as training in Europe)"

Location or travel was mentioned in 631 statements, including the following sample of quotes (see Appendix F):

- "Travel distance - to attend clinics, classes etc. Usually closest venue is 3 hour drive one way. More often it's 6-8 hours drive one way."

- "Finding outstanding educational experiences (clinics, seminars, programs) for myself and students to attend in our region."

- "Distance from dressage hot spots (CA and FL)"

- "weather challenges in our region that impede training" Time was mentioned in 546 statements, including the following sample of quotes (see Appendix F):

- "Started riding later in life - spending a lot of time mastering the basics as an adult" 
- "I don't have 3 challenges however I would say that my greatest challenge is time."

- "As a trainer having enough time off to continue my own education"

- "Understanding of how to navigat the eTrak system. I haven't looked closely, but have personal goals and self education. It's a time factor on my part. Love the quick studies and InDepth studies for this reason.”

Concerns relating to the horses themselves were mentioned 403 times, including the following sample of quotes (see Appendix F):

- "Being able to successfully compete without an expensive, professionally trained horse"

- "Some judges make difficult to compete without breed bias. I would be delighted if USDF choose 6 unlikely breeds to do a symposium with a top trainer. Now that would be something to see."

- "Need a horse to ride"

- "Care for and older schoolmaster horse regarding dietary changes, fitness and other needs of the older semi-retired horse.” USDF-related comments were mentioned 199 times, including the following sample of quotes (see Appendix F):

- "Having to follow up to insure that I received the points I earned with all of the organizations separately. Surely in the age of mega data, much of this information could be linked and verified."

- "Website is difficult to use for educational purposes"

- "USDF seems to only emphasize and aid those riders interested in competing." 
- "Discovering all usdf offers - need to look through the website and dedicate a fair amount of time figuring it all out. Maybe a page - membership benefits - that has all the links to things offered. This may already exist but I haven't found it.” Comments relating to personal issues (excluding time and finances) like outside obligations, time management, feelings of bias and other psychological factors were mentioned 193 times, including the following sample of quotes (see Appendix F):

- "Lack of Cohort: there's a weird clique thing in this area, where if Trainer X is hosting Event $\mathrm{Y}$, Trainer $\mathrm{Z}$ will neither attend, nor recommend it to their students. I completely don't understand it, because there are so few dressage riders here, you'd think we would all want to stick together!"

- "my advanced age - 82"

- "Training and fitness of myself for the goal of competition."

- 'convincing my husband that it's time and money well spent"

Table 10

USDF Members Perceived Obstacles to Success ( $N=1420)$

\begin{tabular}{lcc}
\hline & $\mathrm{N}$ & $\%$ \\
\hline Financial challenges & 936 & 25.43 \\
Educational advancement & 855 & 23.23 \\
Competitive advancement & 749 & 20.35 \\
Location and travel & 631 & 17.14 \\
Availability of time & 546 & 14.83 \\
Horse-related & 403 & 10.95 \\
USDF-related challenges & 199 & 5.41 \\
Personal challenges & 193 & 5.24 \\
\hline
\end{tabular}




\section{Perceptions of USDF Educational Programs}

Participants were asked to rate their level of awareness for various USDF

educational programs. Of the 1,628 individuals that responded to a question about USDF Adult Clinics, 599 (36.79\%) indicated that they had attended a USDF Adult Clinic and $628(38.57 \%)$ indicated that they had considered attending but had not yet done so. Two hundred and thirty-eight members $(14.62 \%)$ had never considered attending and 163 (10.01\%) were unaware of USDF Adult Clinics as a whole (see Table 11).

Of the 599 individuals who had actually attended a USDF Adult Clinic, 578 (96.50\%) rated how beneficial they thought the Clinics were. Three hundred and fiftyeight members (61.94\%) found them to be very beneficial and $154(26.64 \%)$ found them to be mostly beneficial. Sixty-one individuals (10.55\%) found Adult Clinics to be somewhat beneficial and five (0.87\%) found them not at all beneficial (see Table 12$)$.

Of the 1,491 individuals that responded to a question about USDF Jr/YR Clinics, $206(13.82 \%)$ indicated that they had attended the program and $200(13.41 \%)$ indicated that they had considered attending but had not yet done so. Nine hundred and eighty-five individuals $(66.06 \%)$ had never considered attending and $100(6.71 \%)$ were unaware of USDF Jr/YR Clinics entirely (see Table 11).

Of the 206 members indicating they had participated in the USDF Jr/YR Clinics, $197(95.63 \%)$ specified how beneficial they thought the Clinics were. One hundred and fifteen participants $(58.38 \%)$ thought they were very beneficial, $50(25.38 \%)$ thought they were mostly beneficial, and $30(15.23 \%)$ thought they were somewhat beneficial. Two individuals (1.02\%) thought the USDF Jr/YR Clinics were not beneficial at all (see Table 12). 
Of the 1,524 individuals that responded to a question about USDF University programs, $297(19.49 \%)$ indicated that they had attended a program and $348(22.83 \%)$ indicated that they had considered attending but had not yet done so. Four hundred and eighty-five participants (31.82\%) had never considered attending a USDF University program and 394 (25.85\%) were unaware of USDF University programs (see Table 11).

Of the 297 members indicating they had participated in the USDF University programs, 289 (97.31\%) specified how beneficial they thought the programs were. One hundred and forty-seven members (58.87\%) thought they were very beneficial, 102 (35.29\%) thought they were mostly beneficial, and 39 (13.49\%) thought they were somewhat beneficial. One individual ( $0.35 \%)$ thought the USDF University programs were not beneficial at all (see Table 12).

Of the 1,535 individuals that responded to a question about USDF Instructor/Trainer Program Workshops, 281 (18.31\%) indicated that they had attended and $441(28.73 \%)$ indicated that they had considered attending but had not yet done so. Six hundred and eighty-one members (44.36\%) had never considered attending and 132 $(8.60 \%)$ were unaware of USDF Instructor/Trainer Program Workshops (see Table 11).

Of the 281 members indicating they had participated in the USDF Instructor/Trainer Program Workshops, 276 (98.22\%) specified how beneficial they thought the workshops were. One hundred and sixty-two members (58.70 \%) thought they were very beneficial, 64 (23.19\%) thought they were mostly beneficial, and 45 (16.30\%) thought they were somewhat beneficial. Five individuals (1.81\%) thought the USDF Instructor/Trainer Program Workshops were not beneficial at all (see Table 12). 
Of the 1,506 individuals that responded to a question about USDF FEI-Level Trainers Conferences, 133 (8.83\%) indicated that they had attended and 346 (22.97\%) indicated that they had considered attending but had not yet done so. Eight hundred and fifty-eight members (56.97\%) had never considered attending and $169(11.22 \%)$ were unaware of USDF FEI-Level Trainers Conferences (see Table 11).

Of the 133 members indicating they had participated in the USDF FEI-Level Trainers Conferences, $130(97.74 \%)$ specified how beneficial they thought the conferences were. Eighty-six members $(60.15 \%)$ thought they were very beneficial, 30 (23.08\%) thought they were mostly beneficial, and 14 (10.77\%) thought they were somewhat beneficial. No participants indicated that the USDF FEI-Level Trainers Conferences were not at all beneficial (see Table 12).

Of the 1,528 individuals that responded to a question about the USDF Annual Convention, 373 (24.41\%) indicated that they had attended and 618 (40.45\%) indicated that they had considered attending but had not yet done so. Four hundred and eighty-five members (31.74 \%) had never considered attending and $52(3.40 \%)$ were unaware of USDF Annual Convention (see Table 11).

Of the 373 members indicating they had participated in the USDF Annual Convention, 367 (98.39\%) specified how beneficial they thought the conventions were. One hundred and twenty-five members (34.06\%) thought they were very beneficial, 128 (34.88\%) thought they were mostly beneficial, and 107 (29.16\%) thought they were somewhat beneficial. Seven individuals (1.91\%) thought the USDF Annual Conventions were not beneficial at all (see Table 12). 
Of the 1,534 individuals that responded to a question about the USDF L Education Program, 327 (21.32\%) indicated that they had attended and 534 (34.81\%) indicated that they had considered attending but had not yet done so. Five hundred and sixty-nine members (37.09\%) had never considered attending and $104(6.78 \%)$ were unaware of the USDF L Education Program (see Table 11).

Of the 327 members indicating they had participated in the USDF L Education Program, 319 (97.55\%) specified how beneficial they thought the programs were. Two hundred and thirty-eight members (74.61\%) thought they were very beneficial, 56 (17.55\%) thought they were mostly beneficial, and $22(6.90 \%)$ thought they were somewhat beneficial. Only 3 individuals (0.94\%) thought the USDF L Education Programs were not beneficial at all (see Table 12).

Of the 1,498 individuals that responded to a question about USDF Continuing Education for Dressage Judging, 111 (7.41\%) indicated that they had attended and 282 $18.83 \%$ ) indicated that they had considered attending but had not yet done so. Nine hundred and eighty members (65.42\%) had never considered attending and 125 (8.34\%) were unaware of USDF Continuing Education for Dressage Judging (see Table 11).

Of the 111 members indicating they had participated in the USDF Continuing Education for Dressage Judging, 109 (98.12\%) specified how beneficial they thought the programs were. Eighty members (73.39\%) thought they were very beneficial, 22 (20.18\%) thought they were mostly beneficial, and six (5.50\%) thought they were somewhat beneficial. One individual (0.92\%) thought the USDF Continuing Education for Dressage Judging programs were not beneficial at all (see Table 12). 
Of the 1,518 individuals that responded to a question about USDF Sport Horse Seminar, 143 (9.42\%) indicated that they had attended and $430(28.33 \%)$ indicated that they had considered attending but had not yet done so. Seven hundred and twenty-nine members (48.02\%) had never considered attending and $216(14.23 \%)$ were unaware of USDF Sport Horse Seminars (see Table 11).

Of the 143 members indicating they had participated in the USDF Sport Horse Seminars, $138(96.50 \%)$ specified how beneficial they thought the seminars were. Seventy-four members (53.62\%) thought they were very beneficial, 51 (36.96\%) thought they were mostly beneficial, and $12(8.7 \%)$ thought they were somewhat beneficial. One individual $(0.72 \%)$ thought the USDF Sport Horse Seminars were not beneficial at all (see Table 12).

Of the 1,503 individuals that responded to a question about USDF Sport Horse Prospect Development Forum, 63 (4.19\%) indicated that they had attended and 401 (26.68\%) indicated that they had considered attending but had not done so. Eight hundred and eleven members (53.96 \%) had never considered attending and $228(15.17 \%)$ were unaware of the USDF Sport Horse Prospect Development Forums (see Table 11).

Of the 63 members indicating they had participated in the USDF Sport Horse Prospect Development Forum, 60 (95.24\%) specified how beneficial they thought the forums were. Thirty-one members (51.67\%) thought they were very beneficial, 24 $(40.00 \%)$ thought they were mostly beneficial, and five (8.33\%) thought they were somewhat beneficial. No members thought the USDF Sport Horse Prospect Development Forums were not beneficial at all (see Table 12). 
Table 11

Awareness Levels of USDF Educational Programming

\begin{tabular}{|c|c|c|c|c|c|c|c|c|}
\hline & \multicolumn{2}{|c|}{ Have attended } & \multicolumn{2}{|c|}{$\begin{array}{l}\text { Have considered } \\
\text { attending }\end{array}$} & \multicolumn{2}{|c|}{$\begin{array}{c}\text { Have never considered } \\
\text { attending }\end{array}$} & \multicolumn{2}{|c|}{ Unaware } \\
\hline & $\mathrm{N}$ & $\%$ & $\mathrm{~N}$ & $\%$ & $\mathrm{~N}$ & $\%$ & $\mathrm{~N}$ & $\%$ \\
\hline USDF Adult Clinics & 599 & 36.79 & 628 & 38.57 & 238 & 14.62 & 163 & 10.01 \\
\hline USDF Jr-YR Clinics & 206 & 13.82 & 200 & 13.41 & 985 & 66.06 & 100 & 6.71 \\
\hline USDF University programs & 297 & 19.49 & 348 & 22.83 & 485 & 31.82 & 394 & 25.85 \\
\hline $\begin{array}{l}\text { USDF Instructor-Trainer Program } \\
\text { Workshops }\end{array}$ & 281 & 18.31 & 441 & 28.73 & 681 & 44.36 & 132 & 8.60 \\
\hline $\begin{array}{l}\text { USDF FEI-Level Trainers } \\
\text { Conferences }\end{array}$ & 133 & 8.83 & 346 & 22.97 & 858 & 56.97 & 169 & 11.22 \\
\hline USDF Annual Convention & 373 & 24.41 & 618 & 40.45 & 485 & 31.74 & 52 & 3.40 \\
\hline USDF L Education Program & 327 & 21.32 & 534 & 34.81 & 569 & 37.09 & 104 & 6.78 \\
\hline $\begin{array}{l}\text { USDF Continuing Education for } \\
\text { Dressage Judging }\end{array}$ & 111 & 7.41 & 282 & 18.83 & 980 & 65.42 & 125 & 8.34 \\
\hline USDF Sport Horse Seminar & 143 & 9.42 & 430 & 28.33 & 729 & 48.02 & 216 & 14.23 \\
\hline
\end{tabular}


Table 11 (continued)

Awareness Levels of USDF Educational Programming

\begin{tabular}{|c|c|c|c|c|c|c|c|c|}
\hline & \multicolumn{2}{|c|}{ Have attended } & \multicolumn{2}{|c|}{$\begin{array}{l}\text { Have considered } \\
\text { attending }\end{array}$} & \multicolumn{2}{|c|}{$\begin{array}{c}\text { Have never considered } \\
\text { attending }\end{array}$} & \multicolumn{2}{|c|}{ Unaware } \\
\hline & $\mathrm{N}$ & $\%$ & $\mathrm{~N}$ & $\%$ & $\mathrm{~N}$ & $\%$ & $\mathrm{~N}$ & $\%$ \\
\hline $\begin{array}{l}\text { USDF Sport Horse Prospect } \\
\text { Development Forum }\end{array}$ & 63 & 4.19 & 401 & 26.68 & 811 & 53.96 & 228 & 15.17 \\
\hline $\begin{array}{l}\text { USDF Sport Horse Handlers } \\
\text { Clinic }\end{array}$ & 44 & 2.93 & 257 & 17.12 & 915 & 60.96 & 285 & 18.99 \\
\hline
\end{tabular}

Table 12

Participants' Perceptions of Attended USDF Educational Programing

\begin{tabular}{lccccccc}
\hline & \multicolumn{2}{c}{ Very beneficial } & \multicolumn{2}{c}{ Mostly beneficial } & \multicolumn{2}{c}{ Somewhat beneficial } & \multicolumn{2}{c}{ Not at all beneficial } \\
& $\mathrm{N}$ & $\%$ & $\mathrm{~N}$ & $\%$ & $\mathrm{~N}$ & $\%$ & $\mathrm{~N}$ \\
\hline USDF Adult Clinics & 358 & 61.94 & 154 & 26.64 & 61 & 10.55 & 5 \\
USDF Jr-YR Clinics & 115 & 58.38 & 50 & 25.38 & 30 & 15.23 & 2 \\
USDF University programs & 147 & 50.87 & 102 & 35.29 & 39 & 13.49 & 1.02 \\
\hline
\end{tabular}


Table 12 (continued)

Participants' Perceptions of Attended USDF Educational Programing

\begin{tabular}{|c|c|c|c|c|c|c|c|c|}
\hline & \multicolumn{2}{|c|}{ Very beneficial } & \multicolumn{2}{|c|}{ Mostly beneficial } & \multicolumn{2}{|c|}{ Somewhat beneficial } & \multicolumn{2}{|c|}{ Not at all beneficial } \\
\hline & $\mathrm{N}$ & $\%$ & $\mathrm{~N}$ & $\%$ & $\mathrm{~N}$ & $\%$ & $\mathrm{~N}$ & $\%$ \\
\hline $\begin{array}{l}\text { USDF Instructor-Trainer } \\
\text { Program Workshops }\end{array}$ & 162 & 58.70 & 64 & 23.19 & 45 & 16.30 & 5 & 1.81 \\
\hline $\begin{array}{l}\text { USDF FEI-Level Trainers } \\
\text { Conferences }\end{array}$ & 86 & 66.15 & 30 & 23.08 & 14 & 10.77 & 0 & 0.00 \\
\hline USDF Annual Convention & 125 & 34.06 & 128 & 34.88 & 107 & 29.16 & 7 & 1.91 \\
\hline USDF L Education Program & 238 & 74.61 & 56 & 17.55 & 22 & 6.90 & 3 & 0.94 \\
\hline $\begin{array}{l}\text { USDF Continuing Education } \\
\text { for Dressage Judging }\end{array}$ & 80 & 73.39 & 22 & 20.18 & 6 & 5.50 & 1 & 0.92 \\
\hline USDF Sport Horse Seminar & 74 & 53.62 & 51 & 36.96 & 12 & 8.70 & 1 & 0.72 \\
\hline $\begin{array}{l}\text { USDF Sport Horse Prospect } \\
\text { Development Forum }\end{array}$ & 31 & 51.67 & 24 & 40.00 & 5 & 8.33 & 0 & 0.00 \\
\hline $\begin{array}{l}\text { USDF Sport Horse Handlers } \\
\text { Clinic }\end{array}$ & 20 & 46.51 & 17 & 39.53 & 5 & 11.63 & 1 & 2.33 \\
\hline
\end{tabular}


Of the 1,501 individuals that responded to a question about USDF Sport Horse Handlers Clinics, 44 (2.93\%) indicated that they had attended and 257 (17.12\%) indicated that they had considered attending but had not yet done so. Nine hundred and fifteen members (60.96 \%) had never considered attending and $285(18.99 \%)$ were unaware of USDF Sport Horse Handlers Clinics (see Table 11).

Of the 44 members indicating they had participated in the UDSF Sport Horse Handlers Clinics, 43 (97.73\%) specified how beneficial they thought the clinics were. Twenty members (46.51\%) thought they were very beneficial, $17(39.53 \%)$ thought they were mostly beneficial, and five (11.63\%) thought they were somewhat beneficial. One member $(2.33 \%)$ thought the USDF Sport Horse Handlers Clinics were not beneficial at all (see Table 12)

\section{Perceptions of USDF Educational Resources}

Participants were asked to rate their levels of awareness for various USDF educational resources. Of the 1,575 individuals that responded to a question about USDF Podcasts, 251 (15.94\%) indicated that they had utilized this resource and 331 (21.02\%) indicated that they had considered utilizing it, but had not yet done so. Four hundred and forty-eight members (28.44\%) had never considered the utilization of this resource and 545 (34.60\%) were unaware of USDF Podcasts (see Table 13).

Of the 251 members indicating they had utilized UDSF Podcasts, 241 (96.02\%) specified how beneficial they thought it was. One hundred and eleven members (46.06 $\%)$ thought it was very beneficial, $95(39.42 \%)$ thought it was mostly beneficial, and 31 (12.86\%) thought it was somewhat beneficial. Six individuals (1.66\%) thought the USDF Podcasts were not beneficial at all (see Table 14). 
Of the 1,559 individuals that responded to a question about USDF eTRAK, 268 (23.60\%) indicated that they had utilized this resource and $298(19.11 \%)$ indicated that they had considered utilizing it, but had not yet done so. Three hundred and sixty-two members $(23.22 \%)$ had never considered the utilization of this resource and 531 (34.06\%) were unaware of USDF eTRAK (see Table 13).

Of the 368 members indicating they had utilized UDSF eTRAK, 337 (91.58\%) specified how beneficial they thought it was. One hundred and seventy-eight members (52.82\%) thought it was very beneficial, $113(33.53 \%)$ thought it was mostly beneficial and $43(12.76 \%)$ thought it was somewhat beneficial. Three individuals $(0.89 \%)$ thought the USDF eTRAK was not beneficial at all (see Table 14).

Of the 1,544 individuals that responded to a question about USDF H.A.R.T. Program, 28 (1.81\%) indicated that they had utilized this resource and 104 (6.74\%) indicated that they had considered utilizing it, but had not yet done so. Three hundred and twelve members (20.21\%) had never considered the utilization of this resource and 1,100 (71.24\%) were unaware of USDF H.A.R.T. Program (see Table 13).

Of the 28 members indicating they had utilized UDSF H.A.R.T. Program, 26 (92.86\%) specified how beneficial they thought it was. Ten members (38.46\%) thought it was very beneficial, five (19.23\%) thought it was mostly beneficial, and seven (26.92\%) thought it was somewhat beneficial. Four members (15.38 \%) thought the USDF H.A.R.T. Program was not beneficial at all (see Table 14).

Of the 1,557 individuals that responded to a question about USDF social media, $639(41.04 \%)$ indicated that they had utilized this resource and 197 (12.65\%) indicated that they had considered utilizing it, but had not yet done so. Four hundred and thirty- 
three members $(27.81 \%)$ had never considered the utilization of this resource and 288 $(18.50 \%)$ were unaware of USDF social media (see Table 13).

Of the 639 members indicating they had utilized UDSF social media, 441 $(69.01 \%)$ specified how beneficial they thought it was. One hundred and ninety-nine members (38.20\%) thought it was very beneficial, $203(38.96 \%)$ thought it was mostly beneficial, and 109 (20.92\%) thought it was somewhat beneficial. Ten individuals (1.92\%) thought the USDF social media were not beneficial at all (see Table 14).

Of the 1,600 individuals that responded to a question about USDF Connection magazine, 1,477 (92.31\%) indicated that they had utilized this resource and $40(2.50 \%)$ indicated that they had considered utilizing it, but had not yet done so. Another 40 members $(2.5 \%)$ had never considered the utilization of this resource and $43(2.69 \%)$ were unaware of USDF Connection magazine (see Table 13).

Of the 1,477 members indicating they had utilized UDSF Connection magazine, $1,246(84.36 \%)$ specified how beneficial they thought it was. Six hundred and eighty members $(54.57 \%)$ thought it was very beneficial, $385(30.90 \%)$ thought it was mostly beneficial, and $18(13.08 \%)$ thought it was somewhat beneficial. Eighteen members $(1.44$ \%) thought USDF Connection magazines were not beneficial at all (see Table 14).

Of the 1,589 individuals that responded to a question about USDF Guide to Dressage, 992 (62.43\%) indicated that they had utilized this resource and $172(10.82 \%)$ indicated that they had considered utilizing it, but had not yet done so. One hundred and thirty-two members $(8.31 \%)$ had never considered the utilization of this resource and 293 (18.44\%) were unaware of USDF Guide to Dressage (see Table 13). 
Of the 992 members indicating they had utilized UDSF Guide to Dressage, 821 (82.76\%) specified how beneficial they thought it was. Five hundred and forty-seven members $(66.63 \%)$ thought it was very beneficial, $109(23.14 \%)$ thought it was mostly beneficial, and $67(8.16 \%)$ thought it was somewhat beneficial. Seventeen members $(2.07$ \%) thought the USDF Guide to Dressage was not beneficial at all (see Table 14).

Of the 1,556 individuals that responded to a question about USDF Lungeing Manual, 275 (17.67\%) indicated that they had utilized this resource and $236(15.17 \%)$ indicated that they had considered utilizing it, but had not yet done so. Three hundred and forty-eight members $(22.37 \%)$ had never considered the utilization of this resource and 697 (44.79\%) were unaware of the USDF Lungeing Manual (see Table 13).

Of the 275 members indicating they had utilized UDSF Lungeing Manual, 256 (93.09\%) specified how beneficial they thought it was. One hundred and sixty-eight members (65.63\%) thought it was very beneficial, 58 (22.66\%) thought it was mostly beneficial, and $27(10.55 \%)$ thought it was somewhat beneficial. Three individuals (1.17\%) thought the USDF Lungeing Manual was not beneficial at all (see Table 14).

Of the 1,552 individuals that responded to a question about the USDF Teaching Manual, 217 (13.98\%) indicated that they had utilized this resource and 221 (14.24\%) indicated that they had considered utilizing it, but had not yet done so. Four hundred and twenty-seven members $(27.51 \%)$ had never considered the utilization of this resource and 687 (44.27\%) were unaware of the USDF Teaching Manual (see Table 13).

Of the 217 members indicating they had utilized the UDSF Teaching Manual, 203 (93.55\%) specified how beneficial they thought it was. One hundred and thirty-one members (64.53 \%) thought it was very beneficial, 48 (23.65\%) thought it was mostly 
beneficial, and 20 (9.85\%) thought it was somewhat beneficial. Four individuals (1.97\%) thought the USDF Teaching Manual was not beneficial at all (see Table 14).

Of the 1,539 individuals that responded to a question about USDF Show Biz, 120 (7.80\%) indicated that they had utilized this resource and $106(6.89 \%)$ indicated that they had considered utilizing it, but had not yet done so. Three hundred and sixty-two members $(23.52 \%)$ had never considered the utilization of this resource and 951 (61.79\%) were unaware of USDF Show Biz (see Table 13).

Of the 120 members indicating they had utilized UDSF Show Biz, 101 (84.17\%) specified how beneficial they thought it was. Fifty-six members (55.43\%) thought it was very beneficial, $32(31.68 \%)$ thought it was mostly beneficial, and ten $(9.90 \%)$ thought it was somewhat beneficial. Three members $(2.97 \%)$ thought the USDF Show Biz was not beneficial at all (see Table 14).

Of the 1,569 individuals that responded to a question about the USDF Glossary of Judging Terms, 774 (49.33\%) indicated that they had utilized this resource and 165 $(10.52 \%)$ indicated that they had considered utilizing it, but had not yet done so. One hundred and eighty-eight members $(11.98 \%)$ had never considered the utilization of this resource and 442 (28.17\%) were unaware of the USDF Glossary of Judging Terms (see Table 13).

Of the 774 members indicating they had utilized the UDSF Glossary of Judging Terms, $653(84.37 \%)$ specified how beneficial they thought it was. Four hundred and fifty-four members (69.53\%) thought it was very beneficial, $157(24.04 \%)$ thought it was mostly beneficial, and 33 (5.05\%) thought it was somewhat beneficial. Nine members 
(1.38 \%) thought the USDF Glossary of Judging Terms was not beneficial at all (see Table 14).

Of the 1,556 individuals that responded to a question about USDF On the Levels: online subscription, $243(15.62 \%)$ indicated that they had utilized this resource and 442 (28.41\%) indicated that they had considered utilizing it, but had not yet done so. Four hundred and five members (26.03\%) had never considered the utilization of this resource and 466 (29.95\%) were unaware of USDF On the Levels: online subscription (see Table 13).

Of the 243 members indicating they had utilized UDSF On the Levels: online subscription, 203 (83.54\%) specified how beneficial they thought it was. One hundred and thirty respondents (64.04\%) thought it was very beneficial, $39(19.21 \%)$ thought it was mostly beneficial, and $24(11.82 \%)$ thought it was somewhat beneficial. Ten members $(4.93 \%)$ thought the USDF On the Levels: online subscription were not beneficial at all (see Table 14).

Of the 1,555 individuals that responded to a question about USDF On the Levels: DVD, 389 (25.02\%) indicated that they had utilized this resource and 369 (23.73\%) indicated that they had considered utilizing it, but had not yet done so. Four hundred and eighteen members $(26.88 \%)$ had never considered the utilization of this resource and 379 (24.37\%) were unaware of USDF On the Levels: DVD (see Table 13). 
Table 13

Participants' Awareness of USDF Educational Resources

\begin{tabular}{|c|c|c|c|c|c|c|c|c|}
\hline & \multicolumn{2}{|c|}{ I have used the resource } & \multicolumn{2}{|c|}{$\begin{array}{l}\text { I have considered using } \\
\text { the resource }\end{array}$} & \multicolumn{2}{|c|}{$\begin{array}{l}\text { I have never considered } \\
\text { using the resource }\end{array}$} & \multicolumn{2}{|c|}{$\begin{array}{l}\text { I was unaware of the } \\
\text { resource }\end{array}$} \\
\hline & $\mathrm{N}$ & $\%$ & $\mathrm{~N}$ & $\%$ & $\mathrm{~N}$ & $\%$ & $\mathrm{~N}$ & $\%$ \\
\hline USDF Podcasts & 251 & 15.94 & 331 & 21.02 & 448 & 28.44 & 545 & 34.60 \\
\hline USDF eTRAK & 368 & 23.60 & 298 & 19.11 & 362 & 23.22 & 531 & 34.06 \\
\hline USDF HART Program & 28 & 1.81 & 104 & 6.74 & 312 & 20.21 & 1100 & 71.24 \\
\hline USDF social media & 639 & 41.04 & 197 & 12.65 & 433 & 27.81 & 288 & 18.50 \\
\hline $\begin{array}{l}\text { USDF Connection } \\
\text { magazine }\end{array}$ & 1477 & 92.31 & 40 & 2.50 & 40 & 2.50 & 43 & 2.69 \\
\hline $\begin{array}{l}\text { USDF Guide to } \\
\text { Dressage }\end{array}$ & 992 & 62.43 & 172 & 10.82 & 132 & 8.31 & 293 & 18.44 \\
\hline $\begin{array}{l}\text { USDF Lungeing } \\
\text { Manual }\end{array}$ & 275 & 17.67 & 236 & 15.17 & 348 & 22.37 & 697 & 44.79 \\
\hline $\begin{array}{l}\text { USDF Teaching } \\
\text { Manual }\end{array}$ & 217 & 13.98 & 221 & 14.24 & 427 & 27.51 & 687 & 44.27 \\
\hline USDF Show Biz & 120 & 7.80 & 106 & 6.89 & 362 & 23.52 & 951 & 61.79 \\
\hline
\end{tabular}


Table 13 (continued)

Participants' Awareness of USDF Educational Resources

\begin{tabular}{|c|c|c|c|c|c|c|c|c|}
\hline & \multicolumn{2}{|c|}{ I have used the resource } & \multicolumn{2}{|c|}{$\begin{array}{l}\text { I have considered using } \\
\text { the resource }\end{array}$} & \multicolumn{2}{|c|}{$\begin{array}{l}\text { I have never considered } \\
\text { using the resource }\end{array}$} & \multicolumn{2}{|c|}{$\begin{array}{l}\text { I was unaware of the } \\
\text { resource }\end{array}$} \\
\hline & $\mathrm{N}$ & $\%$ & $\mathrm{~N}$ & $\%$ & $\mathrm{~N}$ & $\%$ & $\mathrm{~N}$ & $\%$ \\
\hline $\begin{array}{l}\text { USDF Glossary of } \\
\text { Judging Terms }\end{array}$ & 774 & 49.33 & 165 & 10.52 & 188 & 11.98 & 442 & 28.17 \\
\hline $\begin{array}{l}\text { On the Levels online } \\
\text { subscription }\end{array}$ & 243 & 15.62 & 442 & 28.41 & 405 & 26.03 & 466 & 29.95 \\
\hline On the Levels DVD & 389 & 25.02 & 369 & 23.73 & 418 & 26.88 & 379 & 24.37 \\
\hline
\end{tabular}


Table 14

Participants' Perceptions of USDF Educational Resources

\begin{tabular}{|c|c|c|c|c|c|c|c|c|}
\hline & \multicolumn{2}{|c|}{ Very beneficial } & \multicolumn{2}{|c|}{ Mostly beneficial } & \multicolumn{2}{|c|}{ Somewhat beneficial } & \multicolumn{2}{|c|}{ Not at all beneficial } \\
\hline & $\mathrm{N}$ & $\%$ & $\mathrm{~N}$ & $\%$ & $\mathrm{~N}$ & $\%$ & $\mathrm{~N}$ & $\%$ \\
\hline USDF Podcasts & 111 & 46.06 & 95 & 39.42 & 31 & 12.86 & 4 & 1.66 \\
\hline USDF eTRAK & 178 & 52.82 & 113 & 33.53 & 43 & 12.76 & 3 & 0.89 \\
\hline USDF H.A.R.T. Program & 10 & 38.46 & 5 & 19.23 & 7 & 26.92 & 4 & 15.38 \\
\hline USDF social media & 199 & 38.20 & 203 & 38.96 & 109 & 20.92 & 10 & 1.92 \\
\hline USDF Connection magazine & 680 & 54.57 & 385 & 30.90 & 163 & 13.08 & 18 & 1.44 \\
\hline USDF Guide to Dressage & 547 & 66.63 & 190 & 23.14 & 67 & 8.16 & 17 & 2.07 \\
\hline USDF Lungeing Manual & 168 & 65.63 & 58 & 22.66 & 27 & 10.55 & 3 & 1.17 \\
\hline USDF Teaching Manual & 131 & 64.53 & 48 & 23.65 & 20 & 9.85 & 4 & 1.97 \\
\hline USDF Show Biz & 56 & 55.45 & 32 & 31.68 & 10 & 9.90 & 3 & 2.97 \\
\hline $\begin{array}{l}\text { USDF Glossary of Judging } \\
\text { Terms }\end{array}$ & 454 & 69.53 & 157 & 24.04 & 33 & 5.05 & 9 & 1.38 \\
\hline $\begin{array}{l}\text { On the Levels: online } \\
\text { subscription }\end{array}$ & 130 & 64.04 & 39 & 19.21 & 24 & 11.82 & 10 & 4.93 \\
\hline On the Levels: DVD & 213 & 60.17 & 95 & 26.84 & 41 & 11.58 & 5 & 1.41 \\
\hline
\end{tabular}


Of the 389 members indicating they had utilized UDSF On the Levels: DVD, 354 $(91.00 \%)$ specified how beneficial they thought it was. Two hundred and thirteen individuals (60.17\%) thought it was very beneficial, 95 (26.84\%) thought it was mostly beneficial, and $41(11.58 \%)$ thought it was somewhat beneficial. Five members $(1.41 \%)$ thought the USDF On the Levels: DVD was not beneficial at all (see Table 14)

\section{Frequency of Outside Programming Attended}

A total of 1,591 participants identified the percentage of dressage-related educational resources they utilized outside of what the USDF offered. Five hundred and forty-two members $(34.70 \%)$ indicated that they frequently utilized outside sources and $711(44.69 \%)$ stated they often used sources outside the USDF. Two hundred and sixtysix members (16.72\%) said they rarely used outside educational sources and 72 members (4.53\%) stated they never went outside the USDF to obtain dressage-related educational resources (see Table 15).

Table 15

Use of Educational Resources/Programming Provided by Sources Outside the USDF

\begin{tabular}{lcc}
\hline & $\mathrm{N}$ & $\%$ \\
\hline I frequently use & 542 & 34.07 \\
I often use & 711 & 44.69 \\
I rarely use & 266 & 16.72 \\
I never & 72 & 4.53 \\
Total & 1591 & 100.00 \\
\hline
\end{tabular}




\section{Group Member Organization Use}

One thousand five hundred and nine members selected a percentage range they felt best represented how much of this non-USDF originating educational material was provided to them through a USDF-affiliated Group Member Organization (GMO). Two hundred and fourteen members (14.18\%) felt they used the GMOs for anywhere from 76 to 100 percent of this content, while $181(11.99 \%)$ felt GMOs were responsible for between 51 and 75 percent of this content. Two hundred members $(13.25 \%)$ felt the GMOs provided 26 to 50 percent of their educational content outside the USDF and 265 $(17.56 \%)$ credited them with one to 25 percent. Two hundred and fourteen members $(14.18 \%)$ stated that they did not obtain any educational content relating to dressage outside of what their GMO provided and 435 (28.83\%) did not know (see Table 16). Table 16

Percent Educational Content Outside the USDF Provided by GMOs

\begin{tabular}{lcc}
\hline & $\mathrm{N}$ & $\%$ \\
\hline $76 \%-100 \%$ & 214 & 14.18 \\
$51 \%-75 \%$ & 181 & 11.99 \\
$26 \%-50 \%$ & 200 & 13.25 \\
$1 \%-25 \%$ & 265 & 17.56 \\
None & 214 & 14.18 \\
I don't know & 435 & 28.83 \\
Total & 1509 & 100.00 \\
\hline
\end{tabular}




\section{Outside Educational Resources Used}

One thousand four hundred and eighty-one members identified the resources outside of the USDF or GMOs that they utilized specifically for dressage-related educational content within the last two years. One thousand one hundred and seventy-one members $(62.55 \%)$ listed a trainer as a source, while $784(41.88 \%)$ utilized a local barn's private programing. Four hundred and thirty-seven members $(23.34 \%)$ had utilized a veterinary clinic, $185(9.88 \%)$ a local riding club (non-GMO), and 143 (7.64\%) had utilized programming through Pony Club. Only 117 (6.25\%) had utilized collegiate or university programming, $77(4.11 \%)$ reported obtaining educational content from Extension Services and 53 (2.83\%) had utilized 4-H for dressage-related educational programming.

There were a combined 817 selections (43.64\%) of the option "other" (see Table 17) and 786 text entries explaining the options. There were 250 entries of physical resources such as books, magazines, and DVDs, including the following sample of quotes (see Appendix G):

- "Text and books written by the old masters that are still available in print"

- "Magazine articles online and hard copy"

- "USEF MATERIALS"

- "magazines such as Dressage Today"

Two hundred and eleven entries specified online resources such as YouTube videos, various social media, and specific sites offering educational programming relating to dressage, including the following sample of quotes (see Appendix G):

- "consultation based on an uploaded video" 
- "facebook Dressage Hub it is free"

- "online information, blogs, and forums"

- "YouTube videos posted by trainers"

Two hundred and thirty-five entries mentioned event-based educational programming, such as clinics, travel to work with individual trainers, and unrated or schooling shows, including the following sample of quotes (see Appendix G):

- "WDAA/USEF judge's education program"

- "Open clinics with Certified instructors of the Ecole de legerete"

- "Clinic with European trainers brought here by my trainer"

- "Reining clinics, general training tips from top horse people as seen on direc t.v. regardless of the equipment used. Balance, suppleness, submission to the bit, etc are not just the domain of dressage."

Two hundred and sixty text entries were identifiable by source or organization that provided the educational programming. Sixty-four of these were associations such as the United States Equestrian Federation or the United States Eventing Association and 38 referenced the industry periodical Dressage Today. Thirty-three referenced local barns or trainers having clinics or programming there, 26 listed the individual trainer or clinician they sought out and utilized, and 22 cited DressageTrainingOnline.com (see Appendix G). 
Table 17

Sources of Outside Educational Support $(N=1481)$

\begin{tabular}{lcc}
\hline & $\mathrm{N}$ & $\%$ \\
\hline My trainer & 1171 & 62.55 \\
Local barn & 784 & 41.88 \\
Vet clinic & 437 & 23.34 \\
Local riding club (not GMO) & 185 & 9.88 \\
Pony Club & 143 & 7.64 \\
University-college programming available to & & 6.25 \\
the community & 117 & 4.11 \\
Extension Service & 77 & 2.83 \\
4-H & 53 & 27.83 \\
Other & 521 & 11.54 \\
Other & 216 & 4.27 \\
Other & 80 & \\
Total & 3784 & \\
\hline
\end{tabular}

\section{Outside Educational Resources Used Per Region}

Uses of outside educational resources were then broken down per individual USDF Region. In Region 1, 130 members (63.11\%) utilized their trainer, 82 (39.81\%) a local barn, and $56(27.18 \%)$ a veterinary clinic for educational dressage content. Twentyfour members $(11.65 \%)$ took advantage of programming offered by a non-GMO local riding club, $19(9.22 \%)$ a local venue of higher education, and $16(7.77 \%)$ used Pony Club. Twelve individuals (5.83\%) cited the Extension Service as a source and seven $(3.40 \%) 4-\mathrm{H}$. 
In Region 2, 146 members (64.60\%) utilized their trainer, 108 (47.79\%) a local barn, and $52(23.01 \%)$ a veterinary clinic for educational dressage content. Twenty-four members $(10.62 \%)$ took advantage of programming offered by a venue of higher education and 18 (7.96\%) cited both a non-GMO local riding club and Pony Club. Ten $(4.42 \%)$ cited the Extension Service as a source and six (2.65\%) 4-H.

In Region 3, 113 members (58.25\%) utilized their trainer, 69 (35.57\%) a local barn, and 38 (19.59\%) a veterinary clinic for educational dressage content. Sixteen members $(8.25 \%)$ took advantage of programming offered by a non-GMO local riding club, 14 (7.22\%) Pony Club, and eight (4.12\%) used a local venue of higher education. Six members (3.09\%) cited the Extension Service as a source and four (2.06\%) 4-H.

In Region 4, 152 (65.24\%) utilized their trainer, $113(48.50 \%)$ a local barn, and $66(28.33 \%)$ a veterinary clinic for educational dressage content. Twenty-three members (9.87 \%) utilized both Pony Club and a local venue of higher education, while 22 (9.44\%) used a local non-GMO riding club. Seventeen (7.30\%) cited the Extension Service as a source and $11(4.72 \%) 4-\mathrm{H}$.

In Region 5, 117 (60.94\%) utilized their trainer, $76(39.58 \%)$ a local barn, and 42 $(21.88 \%)$ a veterinary clinic for educational dressage content. Twenty-five members (13.02\%) took advantage of programming offered by a non-GMO local riding club, 12 (6.25\%) a local venue of higher education and seven (3.65\%) used Extension Services. Five members (2.60\%) cited Pony Club as a source and three (1.56\%) 4-H.

In Region 6, 139 members (65.26\%) utilized their trainer, 97 (45.54\%) a local barn, and 48 (22.54\%) a veterinary clinic for educational dressage content. Twenty-seven members $(12.68 \%)$ took advantage of programming offered by a non-GMO local riding 
club, 23 (10.80\%) Pony Club and ten (4.69\%) used 4-H. Seven members (3.29\%) cited the use of a local venue of higher education as a source and five (2.35\%) Extension Services.

In Region 7, 122 (59.22\%) utilized their trainer, $81(39.32 \%)$ a local barn, and 53 $(25.73 \%)$ a veterinary clinic for educational dressage content. Nineteen members $(9.22$ $\%)$ took advantage of programming offered by a non-GMO local riding club, 15 (7.28\%) Pony Club, and nine (4.37\%) used a local venue of higher education. Eight members (3.88\%) cited the Extension Service as a source and three (1.46\%) 4-H.

In Region 8, 127 (65.46\%) utilized their trainer, $81(14.75 \%)$ a local barn, and 35 (18.04\%) a veterinary clinic for educational dressage content. Nineteen members $(9.79$ $\%$ took advantage of programming offered by a non-GMO local riding club, while nine (4.64\%) selected both Pony Club and a local venue of higher education. Seven members (3.61\%) cited the Extension Service as a source and five (2.58\%) 4-H.

In Region 9, 124 (61.69\%) utilized their trainer, 76 (37.81\%) a local barn, and 47 $(23.38 \%)$ a veterinary clinic for educational dressage content. Twenty members $(9.95 \%)$ cited use of Pony Club, 15 (7.46\%) a local non-GMO riding club, and six (2.99\%) a local venue of higher education. Five members (2.49\%) cited the Extension Service as a source and four (1.99\%) 4-H (see Table 18). See Figure 1 for a map of USDF Regions. 
Table 18

Sources of Outside Educational Support per Region

\begin{tabular}{|c|c|c|c|c|c|c|c|c|c|}
\hline & & Vet clinic & $\begin{array}{c}\text { Extension } \\
\text { Service }\end{array}$ & Pony Club & $\begin{array}{l}\text { University- } \\
\text { college } \\
\text { programming }\end{array}$ & $\begin{array}{l}\text { Local } \\
\text { riding } \\
\text { club (not } \\
\text { GMO) }\end{array}$ & $\begin{array}{l}\text { Local } \\
\text { barn }\end{array}$ & $4-\mathrm{H}$ & $\begin{array}{l}\text { My } \\
\text { trainer }\end{array}$ \\
\hline \multirow{2}{*}{ Region 1} & $\mathrm{~N}$ & 56 & 12 & 16 & 19 & 24 & 82 & 7 & 130 \\
\hline & $\%$ & 27.18 & 5.83 & 7.77 & 9.22 & 11.65 & 39.81 & 3.40 & 63.11 \\
\hline \multirow{2}{*}{ Region 2} & $\mathrm{~N}$ & 52 & 10 & 18 & 24 & 18 & 108 & 6 & 146 \\
\hline & $\%$ & 23.01 & 4.42 & 7.96 & 10.62 & 7.96 & 47.79 & 2.65 & 64.60 \\
\hline \multirow{2}{*}{ Region 3} & $\mathrm{~N}$ & 38 & 6 & 14 & 8 & 16 & 69 & 4 & 113 \\
\hline & $\%$ & 19.59 & 3.09 & 7.22 & 4.12 & 8.25 & 35.57 & 2.06 & 58.25 \\
\hline \multirow{2}{*}{ Region 4} & $\mathrm{~N}$ & 66 & 17 & 23 & 23 & 22 & 113 & 11 & 152 \\
\hline & $\%$ & 28.33 & 7.30 & 9.87 & 9.87 & 9.44 & 48.50 & 4.72 & 65.24 \\
\hline \multirow{2}{*}{ Region 5} & $\mathrm{~N}$ & 42 & 7 & 5 & 12 & 25 & 76 & 3 & 117 \\
\hline & $\%$ & 21.88 & 3.65 & 2.60 & 6.25 & 13.02 & 39.58 & 1.56 & 60.94 \\
\hline
\end{tabular}


Table 18 (continued)

Sources of Outside Educational Support per Region

\begin{tabular}{|c|c|c|c|c|c|c|c|c|c|}
\hline & & Vet clinic & $\begin{array}{c}\text { Extension } \\
\text { Service }\end{array}$ & Pony Club & $\begin{array}{l}\text { University- } \\
\text { college } \\
\text { programming }\end{array}$ & $\begin{array}{l}\text { Local } \\
\text { riding } \\
\text { club (not } \\
\text { GMO) }\end{array}$ & $\begin{array}{l}\text { Local } \\
\text { barn }\end{array}$ & $4-\mathrm{H}$ & $\begin{array}{l}\text { My } \\
\text { trainer }\end{array}$ \\
\hline \multirow{2}{*}{ Region 6} & $\mathrm{~N}$ & 48 & 5 & 23 & 7 & 27 & 97 & 10 & 139 \\
\hline & $\%$ & 22.54 & 2.35 & 10.80 & 3.29 & 12.68 & 45.54 & 4.69 & 65.26 \\
\hline \multirow{2}{*}{ Region 7} & $\mathrm{~N}$ & 53 & 8 & 15 & 9 & 19 & 81 & 3 & 122 \\
\hline & $\%$ & 25.73 & 3.88 & 7.28 & 4.37 & 9.22 & 39.32 & 1.46 & 59.22 \\
\hline \multirow{2}{*}{ Region 8} & $\mathrm{~N}$ & 35 & 7 & 9 & 9 & 19 & 81 & 5 & 127 \\
\hline & $\%$ & 18.04 & 3.61 & 4.64 & 4.64 & 9.79 & 41.75 & 2.58 & 65.46 \\
\hline \multirow{2}{*}{ Region 9} & $\mathrm{~N}$ & 47 & 5 & 20 & 6 & 15 & 76 & 4 & 124 \\
\hline & $\%$ & 23.38 & 2.49 & 9.95 & 2.99 & 7.46 & 37.81 & 1.99 & 61.69 \\
\hline
\end{tabular}




\section{Age of Participants}

A total of 1,551 respondents selected a bracket that best represented their age, with $990(63.83 \%)$ selecting an age of 50 or above. The next most represented category was 36-49 years of age, selected by $308(19.86 \%)$ of respondents, followed by 163 (10.51\%) selecting $22-35$ years of age. Least represented was the age of 21 or younger, with $90(5.80 \%)$ individuals identified (see Table 19).

Table 19

Age of Participants

\begin{tabular}{lcc}
\hline & $\mathrm{N}$ & $\%$ \\
\hline 50 or older & 990 & 63.83 \\
$36-49$ years of age & 308 & 19.86 \\
$22-35$ years of age & 163 & 10.51 \\
21 or younger & 90 & 5.80 \\
Total & 1551 & 100.00 \\
\hline
\end{tabular}

\section{Experience in the Equine Industry}

A total of 1,539 respondents indicated how long they had been active within the equine industry as a whole, with a majority of $623(40.48 \%)$ selecting between 21 and 40 years active. The next most represented category was 41-60 years of activity in the equine industry selected by $390(25.34 \%)$ participants. Three hundred and one members (19.56\%) selected 11-20 years of activity and 118 (7.67\%) selected 6-10 years. Sixtynine participants $(4.48 \%)$ selected $0-5$ years active, $32(2.08 \%)$ selected over 60 years of activity, and 6 members $(0.39 \%)$ indicated they had never actually been active within the equine industry (see Table 20). 
Table 20

Years of Activity within the Equine Industry

\begin{tabular}{lcc}
\hline & $\mathrm{N}$ & $\%$ \\
\hline Over 60 Years & 32 & 2.08 \\
41-60 Years & 390 & 25.34 \\
21-40 Years & 623 & 40.48 \\
11-20 Years & 301 & 19.56 \\
6-10 Years & 118 & 7.67 \\
$0-5$ Years & 69 & 4.48 \\
Never Been Active & 6 & 0.39 \\
Total & 1539 & 100.00 \\
\hline
\end{tabular}

\section{Participants Involvement in Ownership}

One thousand five hundred and eighty-seven members entered the number of horses or ponies they had various levels of ownership and utilized for dressage. The minimum number entered was zero animals and the maximum number was 70 animals. The mean number of horses or ponies had various levels of ownership and utilized for dressage was 2.36 with a standard deviation of 3.19 .

When asked how many were ridden or trained for a client, participants entered a between zero and 50 animals. The mean number of animals ridden or trained for a client was 1.26 with a standard deviation of 4.13 .

When discussing horses or ponies produced by their own breeding program, participants entered between zero and 100 animals utilized for dressage purposes. The 
mean number of horses or ponies produced by their own breeding program and utilized for dressage purposes was .98 with a standard deviation of 5.48 .

Asked about horses or ponies free-leased and utilized for dressage purposes, participants entered between zero and 6 animals. The mean number of horses or ponies free-leased and utilized for dressage purposes was 0.09 with a standard deviation of 0.39 .

In regards to horses or ponies leased, participants between zero and 3 animals. The mean number of horses or ponies leased and utilized for dressage purposes was 0.06 with a standard deviation of 0.27 (see Table 21).

Table 21

Levels of Equine Ownership within USDF Members (N=1587)

\begin{tabular}{lllll}
\hline & M & SD & Min & MAX \\
\hline Own & 2.36 & 3.19 & 0.00 & 70.00 \\
$\begin{array}{l}\text { Ride-train for a client (not } \\
\text { personally owned) }\end{array}$ & 1.26 & 4.13 & 0.00 & 50.00 \\
$\begin{array}{l}\text { Have produced via your own } \\
\text { breeding program }\end{array}$ & 0.98 & 5.48 & 0.00 & 100.00 \\
$\begin{array}{l}\text { Free-lease } \\
\text { Lease }\end{array}$ & 0.09 & 0.39 & 0.00 & 6.00 \\
Total & 0.06 & 0.27 & 0.00 & 3.00 \\
\hline
\end{tabular}

\section{Participants Involvement in the Support Industries}

One thousand and thirty-seven members went on to identify their levels of involvement with various support industries within dressage. The respondents were asked to identify the number of horses utilized for dressage purposes with a custom fitted saddle. Responses ranged between zero and 25 horses. The mean number of horses 
utilized for dressage purposes with a custom fitted saddle was 1.47 with a standard deviation of 2.45 .

The respondents asked to identify the number of horses utilized for dressage purposes with their own saddle entered a range between zero and 30 horses. The mean number of horses utilized for dressage purposes with their own saddle was 2.19 with a standard deviation of 3.22 .

The respondents asked to identify the number of horses utilized for dressage purposes that shared a saddle with other horses. The responses ranged from zero to 100 horses. The mean number of horses utilized for dressage purposes that shared a saddle with other horses was 1.66 with a standard deviation of 4.16 .

The respondents asked to identify the number of horses utilized for dressage purposes with a USDF Lifetime Horse Registration or a USDF Horse Identification Number. The responses ranged from zero to 55 horses. The mean number of horses utilized for dressage purposes with a USDF Lifetime Horse Registration or a USDF Horse Identification Number was 2.13 with a standard deviation of 4.24 .

The respondents identified the number of horses utilized for dressage purposes that were insured between zero and 50 horses. The mean number of horses utilized for dressage purposes that were insured was 1.14 with a standard deviation of 2.83 .

The respondents asked to identify the number of horses utilized for dressage purposes which have a routine change of location due to show season. Responses ranged from zero to 50 horses. The mean number of horses utilized for dressage purposes which have a routine change of location due to show season was 0.56 with a standard deviation of 2.42 (see Table 22). 
Table 22

Involvement with Support Industry: Saddles, Registration, Insurance and Seasonal Showing $(N=1037)$

\begin{tabular}{lcccc}
\hline & M & SD & Min & MAX \\
\hline Have a custom-fitted saddle & 1.47 & 2.45 & 0.00 & 25.00 \\
Have their own saddle & 2.19 & 3.22 & 0.00 & 30.00 \\
Share a saddle with other horses & 1.16 & 4.16 & 0.00 & 100.00 \\
$\begin{array}{l}\text { Have a USDF Lifetime Horse } \\
\begin{array}{l}\text { Registration or USDF Horse } \\
\text { Identification Number }\end{array}\end{array}$ & 2.13 & 4.24 & 0.00 & 55.00 \\
$\begin{array}{l}\text { Are insured } \\
\begin{array}{l}\text { Have a routine change of } \\
\text { location due to show season }\end{array}\end{array}$ & 1.14 & 2.83 & 0.00 & 50.00 \\
\hline
\end{tabular}

\section{Participants Involvement with Facilitation of Care}

The 1,037 members went on to identify their levels of involvement in the animals' daily care. Respondents stated that they were the sole facilitator of care between zero horses or ponies utilized for dressage purposes and 63 animals. The mean number of animals that they were sole facilitator of care was 1.85 animals with a standard deviation of 4.02 .

Respondents stated that they boarded at another facility but retained all decisionmaking authority for a minimum of zero horses or ponies utilized for dressage purposes, and a maximum of 50. The mean number of animals they boarded at another facility but retained all decision-making authority was 0.75 animals, with a standard deviation of 2.27 . 
Respondents stated that they boarded at another facility and relied upon that facility to make daily-care decisions, but retained control of major decisions for a minimum of zero horses or ponies utilized for dressage purposes and a maximum of 16 . The mean number of horses they boarded at another facility and relied upon that facility to make daily-care decisions was 0.37 animals with a standard deviation of 1.07 .

Respondents stated that they boarded at another facility which made all decisions for a minimum of zero horses or ponies utilized for dressage purposes and a maximum of 6. The mean number of animals which were boarded at another facility which made all decisions was 0.03 animals, with a standard deviation of 0.31 (see Table 23).

Table 23

Involvement with Support Industry: Facilitator of Equine Care ( $N=1037)$

\begin{tabular}{llccc}
\hline & M & SD & Min & MAX \\
\hline $\begin{array}{l}\text { I am the sole facilitator } \\
\begin{array}{l}\text { I board under another facility's } \\
\text { daily care, but retain all } \\
\text { decision-making authority }\end{array}\end{array}$ & 1.85 & 4.02 & 0.00 & 63.00 \\
$\begin{array}{l}\text { I board at another facility, which } \\
\text { makes daily-care related } \\
\text { decisions for me, but I make all } \\
\text { major decisions }\end{array}$ & 0.37 & 1.07 & 0.00 & 16.00 \\
$\begin{array}{l}\text { I board at a facility that makes } \\
\text { all decisions }\end{array}$ & 0.03 & 0.31 & 0.00 & 50.00 \\
\hline
\end{tabular}

\section{Participants' Involvement with Veterinary Decisions}

One thousand and thirty-seven members again went on to identify their levels of involvement in the animals' veterinary care. Respondents stated that they were the sole communicator with their veterinarian for a minimum of zero horses or ponies utilized for 
dressage purposes, and a maximum of 50. The mean number of animals that they were the sole communicator with their veterinarian was 2.24 animals with a standard deviation of 3.60 .

Respondents stated that they discussed veterinary decisions with their trainer or manager for a minimum of zero horses or ponies utilized for dressage purposes, and a maximum of 100 . The mean number of animals that they discussed veterinary decisions with their trainer or manager was 0.66 animals with a standard deviation of 3.30 .

Respondents stated that they were updated regarding all veterinary decisions made by their trainer or manager for a minimum of zero horses or ponies utilized for dressage purposes, and a maximum of 6 . The mean number of animals where the respondent was updated regarding all veterinary decisions made by their trainer or manager was 0.09 animals with a standard deviation of 0.45 .

Respondents stated that they were updated regarding veterinary decisions solely when they specifically asked questions for a minimum of zero horses or ponies utilized for dressage purposes, and a maximum of 5. The mean number of animals where respondents were updated regarding veterinary decisions when they specifically asked questions was 0.02 animals with a standard deviation of 0.24 (see Table 24). 
Table 24

Involvement with Support Industry: Veterinary Decisions $(N=1037)$

\begin{tabular}{lcccc}
\hline & M & SD & Min & MAX \\
\hline I am sole communicator & 2.24 & 3.60 & 0.00 & 50.00 \\
$\begin{array}{l}\text { I discuss, but make all ultimate } \\
\text { decisions }\end{array}$ & 0.66 & 3.30 & 0.00 & 100.00 \\
$\begin{array}{l}\text { I am updated regarding } \\
\text { decisions made }\end{array}$ & 0.09 & 0.45 & 0.00 & 6.00 \\
\begin{tabular}{l} 
I am only updated when I ask \\
\hline
\end{tabular} & 0.02 & 0.24 & 0.00 & 5.00 \\
\hline
\end{tabular}

\section{Participants Involvement with Farrier-Related Decisions}

One thousand and thirty-seven members identified their levels of involvement in the animals' farrier-related care. Respondents stated that they were the sole communicator with their farrier for a minimum of zero horses or ponies utilized for dressage purposes, and a maximum of 50 . The mean number of animals where the respondents was the sole communicator with their farrier was 2.21 animals with a standard deviation of 3.58 .

Respondents stated that they discussed farrier-related decisions with their trainer or manager for a minimum of zero horses or ponies utilized for dressage purposes, and a maximum of 16 . The mean number of animals where the respondents discussed farrierrelated decisions with their trainer or manager was 0.50 animals with a standard deviation of 1.19 .

Respondents stated that they were updated regarding all farrier-related decisions made by their trainer or manager for a minimum of zero horses or ponies utilized for dressage purposes, and a maximum of 8 . The mean number of animals where all farrier- 
related decisions were made by their trainer or manager was 0.17 animals with a standard deviation of 0.67 .

Respondents stated that they were only updated regarding farrier-related decisions when they specifically asked questions for a minimum of zero horses or ponies utilized for dressage purposes, and a maximum of 11 . The mean number of animals where they were updated regarding farrier-related decisions when they specifically asked questions was 0.02 animals with a standard deviation of 0.36 (see Table 25).

Table 25

Involvement with Support Industry: Farrier $(N=1037)$

\begin{tabular}{lcccc}
\hline & M & SD & Min & MAX \\
\hline I am sole communicator & 2.21 & 3.58 & 0.00 & 50.00 \\
$\begin{array}{l}\text { I discuss, but make all ultimate } \\
\text { decisions }\end{array}$ & 0.50 & 1.19 & 0.00 & 16.00 \\
$\begin{array}{l}\text { I am updated regarding } \\
\text { decisions made }\end{array}$ & 0.17 & 0.67 & 0.00 & 8.00 \\
\begin{tabular}{l} 
I am only updated when I ask \\
\hline
\end{tabular} & 0.02 & 0.36 & 0.00 & 11.00 \\
\hline
\end{tabular}

\section{Disciplines Membership Has Been Active In}

One thousand five hundred and fifty-four members entered a total 6,870 responses when they were asked to select all the equine disciplines they had been actively involved. Dressage was the most popular and was selected by $1,527(81.57 \%)$, trail riding had the next highest participation with 825 members (44.07\%), and third was hunters with 681 (36.38\%). Eventing was fourth with 635 members (33.92\%), pleasure horse was fifth with $513(27.40 \%)$, followed by jumpers (sixth) with $508(27.14 \%)$, and breed shows with 452 (24.15\%). Natural horsemanship was seventh with 287 (15.33\%), driving eighth 
with $208(11.11 \%)$, therapeutic riding ninth with 184 members $(9.83 \%)$ and competitive trail or endurance riding with $149(7.96 \%)$ was tenth most represented. Park horse or saddle seat had been participated in by 142 members $(7.59 \%)$, gymkhana or gaming by $124(6.62 \%)$ ranking twelfth, ranch horsemanship thirteenth with 105 members $(5.61 \%)$, and barrel racing by 99 members (5.29\%) was thirteenth most represented. The other disciplines were participated in by less than 5 percent of respondents and two individuals $(0.11 \%)$ had not ever been active in any equine discipline.

One hundred and forty-five members (7.75\%) selected "other" (see Table 26), with 68 of these text entries related to one of the previously mentioned categories. For example, 15 members indicated western or cowboy dressage outside of the provided “dressage” category. Twenty-three specified foxhunting, 14 members specified children's programming such as 4-H or Pony Club, five indicated breed specific or gaited shows, and four specified side saddle. Some of the singular entries of note included (see Appendix H):

- "equine clicker training,"

- "Mounted Sheriff's Posse"

- "stunt riding at dinner theater" 
Table 26

Equine Disciplines Members Are/Have Been Active $(N=1554)$

\begin{tabular}{|c|c|c|}
\hline & $\mathrm{N}$ & $\%$ \\
\hline Dressage & 1527 & 81.57 \\
\hline Trail Riding & 825 & 44.07 \\
\hline Hunters & 681 & 36.38 \\
\hline Eventing & 635 & 33.92 \\
\hline Pleasure Horse & 513 & 27.40 \\
\hline Jumpers & 508 & 27.14 \\
\hline Breed Shows & 452 & 24.15 \\
\hline Natural Horsemanship & 287 & 15.33 \\
\hline Driving & 208 & 11.11 \\
\hline Therapeutic Riding & 184 & 9.83 \\
\hline Competitive Trail-Endurance & 149 & 7.96 \\
\hline Park Horse-Saddle Seat & 142 & 7.59 \\
\hline Gymkhana-Gaming & 124 & 6.62 \\
\hline Ranch Horsemanship & 105 & 5.61 \\
\hline Barrel Racing & 99 & 5.29 \\
\hline Reining & 88 & 4.70 \\
\hline Racing & 80 & 4.27 \\
\hline Vaulting & 60 & 3.21 \\
\hline Polo & 56 & 2.99 \\
\hline I have not ever been actively involved & 2 & 0.11 \\
\hline Other & 145 & 7.75 \\
\hline
\end{tabular}




\section{CHAPTER V}

\section{Summary, Conclusions, and Recommendations}

\section{Purpose of the Study}

The purpose of this study was threefold: to identify educational opportunities available to current USDF members to assist them in reaching their goals within the organization, both regionally as well as nationally; to evaluate current USDF-offered programming; and to identify the top perceived handicaps toward members' goals in the industry. Once this information can be ascertained, appropriate changes can be made to a variety of programs to assist with strengthening the education available to our developing rider curriculum can both become more effective and address any previously unknown obstacles on a national or regional basis.

\section{Objectives of the Study}

The objectives of the study were reflected in the following research questions:

1. What Regions were USDF members involved in educational activities?

2. What was the participants' level of involvement in both the equine and dressage industries?

3. What were the USDF members' goals with their USDF membership?

4. What were the three most significant perceived obstacles to achieving their goals for the membership?

5. What was the level of awareness of available USDF educational programming?

6. What were the USDF members' evaluations of USDF programming they have utilized? 
7. What resources outside of the USDF have members used for their education in dressage?

\section{Summary and Conclusions}

While USDF generates informational mailings based on member's home addresses, between 8.16 percent and 33.60 percent of members surveyed were not active within their own USDF Region (see Table 27; Figure 1). Due to these numbers, it may be beneficial for the USDF to allow members a venue to make the organization aware of additional USDF Regions where they are active, as this may increase the relevancy of USDF communications, and awareness and participation in educational programming.

Table 27

Percentage of Members Not Active in Home Region

\begin{tabular}{lc}
\hline & $\%$ \\
\hline Region 1 & 23.41 \\
Region 2 & 30.46 \\
Region 3 & 33.60 \\
Region 4 & 15.71 \\
Region 5 & 8.16 \\
Region 6 & 9.46 \\
Region 7 & 20.56 \\
Region 8 & 14.22 \\
Region 9 & 13.33 \\
\hline
\end{tabular}

This recommendation is supported by the theme throughout the survey of members' uncertainty in ways the USDF could assist them in their goals. While locating 
competitive and educational resources in their area is a major challenge to many member's successes (see Appendix F; Table 9), having additional exposure to the knowledge of these resources in their geographic region as opposed to their USDF Region may be helpful for those members who may be on the border of these Regions.

The majority of members maintained a Participating Membership (68.11\%), with GMO memberships as the second-most popular (34.46\%). This could possibly lead many members to the misconception that the USDF is not purely an educational organization, but heavily involved in competitive regulation as well. Actual Educational Memberships were the least popular membership type among those surveyed (0.37\%), and with the nature of the sport (where judges' comments on competitive score cards are the ultimate education for many), this is a difficult distinction to make and communicate to such a diverse population.

\section{Professional Networking Database}

The most popular credential USDF members look for when choosing a dressage instructor was personal recommendation (75.21\%). The second most-popular desired credential was awarded USDF medals (52.03\%) and third USDF Certified Instructors (42.36\%), which indicates the membership strongly values the opinions provided by the USDF and its membership (see Table 5). This, combined with the overlapping of Regional participation, leads to the suggestion of some sort of web-based resource network specifically for USDF members and industry professionals. Many members are already utilizing the Centerline Star system to look for instructors with competitive successes, and overwhelmingly seek either personal observation or word-of-mouth recommendations as well (see Appendix C). Centrally collecting this information in a 
Yelp or LinkedIn-type formatted database may well address a majority of members' most pressing issues: locating accessible quality resources that align with their individual goals at a price they can accommodate.

Additionally, when members were asked to list their greatest obstacles to success, one hundred and eighty-five statements contained the word "finding" including the following sample of quotes (see Table 9; see Appendix F):

- "Finding a school master that I can afford and is adult amateur friendly."

- "Finding good instructors that are available on weekends. Many top trainers only do lessons during the week. does not fit with my work schedule"

- "Not being able to find what I need for information on the USDF or USEF websites"

- "Finding sponsors to help achieve my goals"

These instances again supported the recommendation of a centralized database of available resources available to members. With a database such as this moderated by the USDF, analytics would further provide statistics for the organization on categories of resources which may be lacking in certain areas at any time, which would be helpful for program development and allocation of organizational resources as well.

\section{Regional Priorities}

Nationally, the reasons for USDF membership remained fairly consistent with competitive achievement and education for the horse or rider ranking highest in all Regions but 3 and 6 (selecting "education for dressage judging" and "other," respectively). When members were asked to select one primary reason for membership, these three ("advancement in competition," "education for training of the horse," and 
"education for instruction of the rider") remained the top three choices in all regions except Region 6, which exhibited "other" as the third-most popular choice (12.68\%). Further research would be helpful in identifying Region 3's priority for membership. Due to its remote geographic location one could hypothesize that other aspects of the dressage industry (breeding, etc.) may be flourishing there (see Table 8).

\section{Programming}

Members indicated high levels of benefit on programs they attended, signifying that the programs themselves are strong and participants are confident in them. With strong ratings, allowing for participants to publicly review programs to other members would be advantageous, as increased levels of participation and engagement should be the highest priority (see Table 11).

Awareness levels among members of educational programming indicated that the majority of members were aware of programs (see Table 28), but perhaps did not feel that some of them were relevant to them, as some programs had high percentages in the “never considered attending" category (see Table 10). Making this population aware of ways in which these programs might impact their goals and improve the industry would be advantageous in addressing these numbers. Specifically, the sport horse focused programming had higher numbers in the "have never considered attending" category (see Table 10), but many members still cited difficulty in accessing appropriate horses as a major obstacle to their success (10.95\%; see Table 9). Members who might be made aware of ways in which they could support the development of the American dressage horse would be empowered to address one of their largest obstacles. Demographic data indicated the majority of members surveyed were the sole facilitator of care for their 
horses (see Table 22), as well as had discussions with their veterinarian (see Table 23) and farrier (see Table 24), which would indicate at least a potential level of interest in this aspect of the industry.

The number of members who considered attending various programs but have not yet done so would be worth canvassing in the future to identify ways to allow these individuals to engage in the programs. Since location and cost was overwhelmingly cited as a problem for members, perhaps developing a more economical online portion of the programs to augment fewer physical requirements would make it more accessible to these members, much like mixed-format courses in higher education that allow for a mix of online and on-campus sessions. Web content such as social media and web video was cited by members as an outside educational resource as well (see Appendix G), which is again supportive of a recommendation for an increase in USDF- sponsored online programs.

A uniform evaluation consistently distributed to program participants would create a useful databank for various GMOs or the USDF to reflect upon areas of improvement as well as strengths in their educational programming, both nationally and per USDF Region. 
Table 28

Levels of Awareness for Educational Programs

\begin{tabular}{lcc}
\hline & $\mathrm{N}$ & $\%$ \\
\hline USDF Adult Clinics & 1465 & 89.98 \\
USDF Jr-YR Clinics & 1391 & 93.29 \\
USDF University programs & 1130 & 74.14 \\
USDF Instructor-Trainer Program & 1403 & 91.40 \\
Workshops & & \\
USDF FEI-Level Trainers & 1317 & 88.77 \\
Conferences & 1476 & 96.60 \\
USDF Annual Convention & 1430 & 93.22 \\
USDF L Education Program & & 81.01 \\
USDF Continuing Education for & 1373 & 85.77 \\
Dressage Judging & 1302 & \\
USDF Sport Horse Seminar & 1216 & 84.83 \\
USDF Sport Horse Prospect & & \\
Development Forum & & \\
USDF Sport Horse Handlers & & \\
Clinic & & \\
\hline
\end{tabular}

\section{Educational Resources}

Awareness levels for many of the listed resources were much lower than that of the educational programs, which may be problematic in that an online database or written resources are typically much easier to access for a member, in regards to both cost and geographic location (see Table 29). USDF Connection, the membership's periodical, predictably had the highest level of awareness (97.31\%) and may be a good venue to periodically feature these other resources to raise awareness. While most members rated 
these resources as beneficial, the numbers were not as good as those for the educational programming (see Tables $11 \& 13$ ), leaving room for further research in ways to improve these resources. Again, a uniform resource evaluation may be advantageous here to isolate both strengths and areas of improvement for these items.

Table 29

Levels of Awareness for Educational Resources

\begin{tabular}{lcc}
\hline & $\mathrm{N}$ & $\%$ \\
\hline USDF Podcasts & 1030 & 65.40 \\
USDF eTRAK & 1028 & 65.93 \\
USDF HART Program & 444 & 28.76 \\
USDF social media & 1269 & 81.50 \\
USDF Connection & 1557 & 97.31 \\
USDF Guide to Dressage & 1296 & 81.56 \\
USDF Lungeing Manual & 859 & 55.21 \\
USDF Teaching Manual & 865 & 55.73 \\
USDF Show Biz & 588 & 38.21 \\
$\begin{array}{l}\text { USDF Glossary of Judging } \\
\text { Terms }\end{array}$ & 1127 & 71.83 \\
$\begin{array}{l}\text { On the Levels: online } \\
\text { subscription }\end{array}$ & 1090 & 70.06 \\
On the Levels: DVD & 1176 & 75.63 \\
\hline
\end{tabular}

\section{USDF Infrastructure}

Many members cited confusion with USDF infrastructure as well as uncertainty in how the organization could benefit them. Changing paperwork requirements, multiple 
required registrations for various situations and difficulty locating information on the USDF website were cited. Perhaps a promoted hotline or designated point of contact within the organization to assist with these logistics might be helpful (see Appendix G).

\section{Collaboration with Other Agencies or Sources of Support}

The simple geographic size of the United States in comparison to other competitive countries makes it logistically impossible to provide programming that is geographically accessible to all members. An emphasis on collaboration with local resources may be another solution in addition to online components. All Regions indicated a high level of educational content received by their members through both local trainers and barns ( $62.55 \%$ and $41.88 \%$, respectively) as well as their vet clinics (23.34\%; see Table 16). Since this is an infrastructure that is already in place, the USDF should take steps to be sure that these educational opportunities are networked to their organization wherever possible. Targeted advertising of the USDF University program to give these programs credence through the USDF would benefit all parties if done in a collaborative manner. The fact that financial difficulties were the number one challenge mentioned by members $(25.43 \%)$ may support the idea of developing educational classes specifically addressing ways to proceed in the industry economically: networking, gaining the most of available resources, and applying for available grants and funding. These are subject matters that may easily allow for collaboration at higher education or Cooperative Extension venues. Many members were not sure if programming they attended were GMO sponsored or not (28.83\%), so more definitive advertising on such sponsorships is recommended. Support from the USDF towards the GMOs' increased networking with these localized sources would be valuable. 
Other resources did not have as high a frequency of use. Collaboration with local universities and Extension offices certainly could absolutely be increased assuming their availability, as the numbers of members receiving educational content from either venue remained fairly low (6.25\% and 4.11\%, respectively). Further research within Regional areas is recommended to help extrapolate the details on where and how these collaborations could be useful, since it is unknown if these resources are unavailable altogether in certain areas, incompatible, or simply underutilized (see Table 17).

Member demographics showed a population that tended to be heavily involved in their animals care, so networking educational content through vet clinics, farriers, and local barns is again a concept supported through this portion of the survey. Members' highest average among the options for involvement in daily care was being the sole facilitator of care for an average of 1.85 horses, and the sole communicator with the veterinarian for an average of 2.24 horses, indicating a population likely to be interested in their horse's day-to-day lives (see Tables $22 \& 23$ ). Members were also usually the sole communicator with the farrier (see Table 24), leading to the possibility of educational interests in networking the veterinarian, farrier, and dressage goals together to a more efficient use of the owner's resources.

Members also showed a great deal of involvement in other equine disciplines; in fact, 18.43 percent of those surveyed selected they had not been active in dressage as a discipline. Members were most active (after dressage at $81.57 \%$ ) as trail riders (44.07\%), hunters $(36.38 \%)$, eventers $(33.92 \%)$ and pleasure horse riders (27.40\%). Educational content to specifically address the needs of both horses and riders who span multidisciplines could have potential. 


\section{Recommendations}

In summary the following recommendations are offered in regards to USDF infrastructure:

1. Record members' active USDF Regions.

2. Develop a moderated online database from which members will locate resources

3. Allow for membership to comment upon and rate these resources.

4. Promote a designated point of contact for help within the organization. In regards to programming:

5. Increasing awareness levels of educational resources by utilizing communication vectors that members are more aware of.

6. Increasing members' knowledge on how certain educational programs could benefit them, despite being outside their typical area of study.

7. Developing educational programming with more of a mixed-media priority.

8. Development of educational programming that assists members who attempt to utilize their dressage skills (or horses) in multiple or other disciplines.

9. Development of educational programming specifically addressing membership's challenges: networking and obtaining resources.

10. Aggressive networking of educational programming outside the USDF to make them more available to remote locations: promotion of the USDF University, collaboration with higher education, Cooperative Extension Services and local veterinary clinics.

In regards to future research:

11. Identify the third-priority goals of the members of Region 3. 
12. Regularly collect formalized evaluations from members upon completion of programs or utilization of resources. 


\section{REFERENCES:}

Al-Busafi, M., Ramadan, W. M., \& Kilani, H. (2012). Analysis of Selected International and National Coach Education Programs. Ovidius University Annals, Series Physical Education and Sport, XII. Retrieved from: http://www.analefefs.ro/anale-fefs/2012/issue-2-s/pe-autori/12.pdf

Ary, D., Jacobs, L. C., \& Razavieh, A. (2006). Introduction to Research in Education (7th ed.). Belmont, CA: Thomson Wadsworth.

Bryant, J. O. (2008). Olympic Equestrian: A Century of International Horse Sport. Lexington, KY: Blood Horse Publications.

Bryant, J. O. (2006). The USDF Guide to Dressage. North Adams, MA: Storey Publishing.

Christian, L. M., Dillman, D. A., \& Smyth, J. D. (2007). Helping Respondents Get it Right the First Time: The Influence of Words, Symbols and Graphics in Web Surveys. Public Opinion Quarterly, 71, 113-125.

Christian, L. M., Dillman, D. A., \& Smyth, J. D. (2005). The Effects of Mode and Format on Answers to Scalar Questions in Telephone and Web Surveys ${ }^{1}$. Retrieved from http://www.sesrc.wsu.edu/dillman/papers/2006/theeffectsofmodeandformat.pdf

Gilbert, W. \& Trudel, Pierre (1999). An Evaluation Strategy for Coach Education Programs. Journal of Sport Behaviour, (n.v.). Retrieved from: http://www.thefreelibrary.com/_/print/PrintArticle.aspx?id=54895646

Gribbons, A. (2012a). Forward Bound After A Last Look Back. Retrieved from: http://www.chronofhorse.com/article/forward-bound-after-last-look-back

Gribbons, A. (2012b). Looking Beyond the Olympics. Retrieved from: http://www.chronofhorse.com/article/looking-beyond-olympics

Gribbons, A. (2012c). Practice Makes Perfect. Retrieved from: http://www.chronofhorse.com/article/practice-makes-perfect-0

Gribbons, A. (2012d). The Olympics Were Everything We Feared. Retrieved from: http://www.chronofhorse.com/article/olympics-were-everything-we-feared

Hammerschmidt, P., Murphy, A., Youatt, J., Sawyer, C., \& Andrews, S. (1994). Evaluating Curriculum Effectiveness by Asking the Users. Journal of Extension, 32, (3). Retrieved from: http://www.joe.org/joe/1994october/iw4.php/

Markel/USEF Young Horse Dressage Program. (2014, February 7). Retrieved from: https://www.usef.org/documents/disciplines/dressage/2014MarkelUSEFSelection Events.pdf 
Miller, L. E., \& Smith, K. L. (1983). Handling Nonresponse Issues. Journal of Extension, 45-50. Retrieved March 16, 2016.

Morgan, M. H. (Ed.). (2006). The art of horsemanship. Courier Corporation.

On The Levels (n.d.). About. Retrieved on 26 February 2016 from https://www.onthelevels.com/index.php.

Redline, Cleo (2013). Clarifying Categorical Concepts in a Web Survey. Public Opinion Quarterly, 77, 89-105.

Robinson, J. P., Shaver, P. R., \& Wrightsman, L. S. (1991). Criteria for scale selection and evaluation. In J. P. Robinson, P. R. Shaver, \& L. S. Wrightsman (Eds.). Measures of personality and social psychological attitudes (pp. 1-16) New York: Academic Press.

Robinson, P. E. (2014). Foundations of Sports Coaching. New York: Routledge.

Sawano, M. (2010). The Rise and Fall of Corporate Sports Programs. Japanese Research in Business History, 27(0), 27-45.

Spanische Hofreitschule (n.d.). Welcome to the Spanish Riding School in Vienna. Retrieved from: http://www.srs.at/en/

U.C. Davis School of Veterinary Medicine. (2008, January). CEH Horse Report: A Publication of the Center for Equine Health. Retrieved from: http://www.vetmed.ucdavis.edu/ceh/docs/horsereport/pubs-HR26-1-bkm-sec.pdf

United States Dressage Federation. (15 December 2014). United States Dressage Federation 2015 Glossary of Judging Terms [PDF]. Retrieved from http://www.usdf.org/EduDocs/Competition/Glossary_2015_Final_No_POT_ref.p df.

United States Dressage Federation (2015). 2015 Member Guide. Lexington: United States Dressage Federation.

United States Dressage Federation (2016a). eTRAK: USDF Online Learning. Retrieved on 25 February 2016 from http://www.usdf.org/e-trak/.

United States Dressage Federation (2016b). USDF Official Podcast. Retrieved on 25 February 2016 from http://usdf.podbean.com/.

United States Dressage Federation (n.d.a). About USDF. Retrieved from: http://www.usdf.org/about/about-usdf/

United States Dressage Federation (n.d.b). Group Membership (GM) FAQs. Retrieved from: http://www.usdf.org/faqs/gmo.asp 
United States Dressage Federation (n.d.c). Group Member Organizations (GMOs). Retrieved from: http://www.usdf.org/clubs/gmo/

United States Dressage Federation (n.d.d). History of dressage. Retrieved from: http://www.usdf.org/about/about-dressage/history.asp

United States Dressage Federation (n.d.e). History of USDF. Retrieved from: http://www.usdf.org/about/about-usdf/history.asp

United States Dressage Federation. (n.d.f). Photostream [Flickr page]. Retrieved 26 February 2016 from https:/www.flickr.com/photos/98929906@N03/.

United States Dressage Federation. (n.d.g). Publications. Retrieved on 26 February 2016 from http://www.usdf.org/Publications/.

United States Dressage Federation. (n.d.h). Timeline [Facebook page]. Retrieved 26 February 2016, from https://www.facebook.com/United-States-DressageFederation-Official-Page-113430362040/.

United States Dressage Federation. (n.d.i). Tweets [Twitter page]. Retrieved 26 February 2016, from https://twitter.com/USDF.

United States Dressage Federation (n.d.j) University. Retrieved from: http://www.usdf.org/education/university/index.asp

United States Dressage Federation (n.d.k) USDF Governance. Retrieved from: http://www.usdf.org/docs/about/about-usdf/governance/OrgChart.pdf

United States Dressage Federation. (n.d.1). USDF Region Map. Retrieved from: http://www.usdf.org/clubs/region_map.asp

United States Dressage Federation (n.d.m). Which membership is right for me? Retrieved from: http://www.usdf.org/join/

United States Dressage Federation. (n.d.n). Videos [YouTube page]. Retrieved 26 February 2016 from https:/www.youtube.com/user/USDFORG/videos.

USDF Online Store. (n.d.). USDF Publications/Flash Drives. Retrieved on 26 February 2016 from https://www.usdf.org/cgibin/commerce.exe? search=action\&category=UPUB.

Wholey, J. S., Hatry, J. P., \& Newcomer, K. E. (Eds.). (2010). Handbook of Practical Program Evaluation. San Francisco, CA: Jossey-Bass. 
APPENDICES 
APPENDIX A

Instrument 


\section{USDF Members Perceptions of Educational Landscape}

Q1 Please answer the following seven questions as they relate to your involvement with the dressage industry and the USDF: Which USDF Region represents the location of your home address? Please select only one.

O Region 1 (PA, NJ, DE, MD, VA, NC, District of Columbia, WV's Morgan, Berkeley and Jefferson counties) (1)

O Region 2 (WI, MI, IL, IN, KY, OH, WV's counties other than Morgan, Berkeley and Jefferson) (2)

O Region 3 (TN, AL, GA, FL, SC) (3)

O Region 4 (ND, SD, NE, KS, MN, IA, MO) (4)

O Region 5 (eastern MT, WY, UT, CO, AZ, NM, western TX) (5)

O Region 6 (AK, WA, OR, ID, western MT) (6)

O Region 7 (CA, NV, HI) (7)

O Region 8 (ME, NH, VT, NY, MA, RI, CT) (8)

O Region 9 (TX, OK, AR, LA, MS, eastern TX) (9)

O Region 10 (International) (10)

Q2 Which USDF Region(s) do you typically participate in USDF programming or events? Please check all that apply.

Region 1 (PA, NJ, DE, MD, VA, NC, District of Columbia, WV's Morgan, Berkeley and Jefferson counties) (1)

Region 2 (WI, MI, IL, IN, KY, OH, WV's counties other than Morgan, Berkeley and Jefferson) (2)

Region 3 (TN, AL, GA, FL, SC) (3)

Region 4 (ND, SD, NE, KS, MN, IA, MO) (4)

Region 5 (eastern MT, WY, UT, CO, AZ, NM, western TX) (5)

Region 6 (AK, WA, OR, ID, western MT) (6)

Region 7 (CA, NV, HI) (7)

Region 8 (ME, NH, VT, NY, MA, RI, CT) (8)

Region 9 (TX, OK, AR, LA, MS, eastern TX) (9)

Q Region 10 (International) (10)

I do not participate in USDF programming or events (11)

Q3 Which type of USDF membership do you have? Please check all that apply.

口 Participating Membership (1)

Youth Participating Membership (2)

Group Membership (3)

Education Membership (4)

I don't know (6) 
Q4 When seeking dressage instruction, which of the following credentials do you consider important? Please select all that apply.

USDF medals (Bronze, Silver, Gold) (1)

USDF Certified Instructors (2)

United States Eventing Association Instructor Certification Program credentials (3)

Certified Horseman's Association Certification (4)

- American Riding Instructor Certification (5)

- United States Hunter Jumper Association's Trainer Certification Program credentials (6)

Collegiate degree (7)

口 Personal recommendations (10)

Other (please list): (8)

Other (please list): (9)

Q5 For which of the following purposes do you utilize your USDF membership? Please select all that you consider important.

ㅁ Equine breed promotion (1)

Advancement in competition (2)

- Certifications (4)

Education for dressage judging (5)

Education for training of the horse (6)

Education for instruction of the rider (7)

Industry trends/news (8)

Member perks/discounts (9)

Other: (10)

Q6 What is the primary purpose of your USDF membership? Please select only the most important attribute.

O Equine breed promotion (1)

O Advancement in competition (2)

O Certifications (4)

Education for dressage judging (5)

O Education for training of the horse (6)

Education for instruction of the rider (7)

Industry trends/news (8)

O Member perks/discounts (9)

O Other: (10) 
Q7 Please list your three greatest challenges to personally fulfilling your goals with the USDF:

First challenge: (1)

Second challenge: (2)

Third challenge: (3)

Q8 Please answer the following question by selecting the answer that most represents your experience with the following USDF educational programs:

\begin{tabular}{llll}
\multicolumn{1}{c}{ I have } & \multicolumn{1}{c}{ I have } & \multicolumn{1}{c}{ I have } & \multicolumn{1}{c}{ I was } \\
attended this & considered & never & unaware of \\
program (1) & $\begin{array}{l}\text { attending, but } \\
\text { have not yet } \\
\text { done so (2) }\end{array}$ & $\begin{array}{l}\text { considered } \\
\text { attending this }\end{array}$ & $\begin{array}{l}\text { program (3) } \\
\text { this program }\end{array}$ \\
& $\bigcirc$ & $\bigcirc$ & $\bigcirc$
\end{tabular}

Adult Clinics (1)

USDF

$\mathrm{Jr} / Y R$ Clinics (2)

USDF

University

programs (3)

USDF

Instructor/Trainer

Program

Workshops (4)

USDF

FEI-Level

Trainers

Conferences (5)

USDF

Annual

Convention (6)

USDF L

Education

Program (7)

USDF

Continuing

Education for

Dressage Judging

(8)

$$
\text { USDF }
$$

Sport Horse

Seminar (9)

USDF

Sport Horse

Prospect 
Development

Forum (10)

USDF

Sport Horse

Handlers Clinic

Answer If Please answer the following question by selecting the answer that most represents your experience... - I have attended this program Is Selected

Q9 Please answer the following question by selecting the option that best represents how beneficial each of the programs you attended were.

Q10 Please answer the following question by selecting the answer that most represents your experience with the following USDF educational resources:

I have

utilized this resource (1)

USDF

Podcasts (1)

USDF

eTRAK (2)

USDF

H.A.R.T.

Program (3) USDF

social media (4)

USDF

Connection

magazine (5)

USDF

Guide to

Dressage (7)

USDF

Lungeing

Manual (8)

USDF

Teaching

Manual (9)

USDF

Show Biz (10)

USDF

Glossary of
I have

considered

utilizing, but

have not yet

done so (2)

$\mathrm{O}$

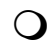

O

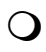

O
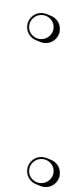

O

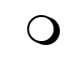

O

0

$\bigcirc$

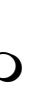

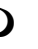

I have not considered utilizing (3) unaware of this resource

(4)

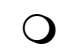

\section{O}

O

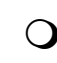

$\bigcirc$

O

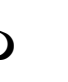


Judging Terms

(11)

On the

Levels: online

subscription

On the

Levels: DVD

Answer If Choose Please answer the following question by selecting the answer that most represents your experience with the following USDF educational resources: - I have utilized this resource Is Selected

Q11 Please answer the following question by selecting the option that best represents how beneficial each of the programs you attended were.

Q12 Almost done! Please answer the following three questions as they relate to other educational opportunities available to you (outside of the USDF). Which of the following best represents your use of educational dressage programming other than what the USDF offers:

O I never use dressage-related educational resources outside of the USDF (1)

O I rarely use dressage-related educational resources outside of the USDF (2)

O I often use dressage-related educational resources outside of the USDF (3)

O I frequently use dressage-related educational resources outside of the USDF (4)

If I never have access to dres... Is Selected, Then Skip To End of Block

Q13 Of the non-USDF programming available to you, what percent is organized through a USDF-affiliated Group Member Organization (GMO)?
O None (1)
O $1 \%-25 \%(6)$
O $26 \%-50 \%(2)$
O $51 \%-75 \%(3)$
O $76 \%-100 \%(4)$
O I don't know (5)

Q14 What outside resources have you utilized within the last two years for dressage-related content? Select all that apply.

- Vet clinic (1)

Extension Service (2)

4-H (10)

Pony Club (3)

University/college programming available to the community (4)

Local riding club (not GMO) (5)

Local barn (6) 
My trainer (may or may not be USDF member) (11)

$\square$ Other (7)

$\square$ Other (8)

$\square$ Other (9)

Q15 Please answer the following questions regarding your personal involvement in the industry. There are up to five, depending upon your answers. How many horses or ponies that you utilize for dressage fit in the following categories? Please enter a number for each.

Own: (1)

Free-lease: (2)

Lease (5)

Ride/train for a client (not personally owned) (8)

Have produced via your own breeding program: (3)

Total (4)

If Total Is Equal to 0, Then Skip To End of Block

Q19 Of these animals utilized for dressage, please enter a numerical value for how many:

Have a custom-fitted saddle? (1)

Have their own saddle? (2)

Share a saddle with other horses? (3)

Number? (4)

Have a USDF Lifetime Horse Registration or USDF Horse Identification

Are insured? (5)

Have a routine change of location due to show season? (6)

Q16 With regard to daily care: of the animals you personally own for dressage, please enter the number of animals for which the following statements are true:

I am the sole facilitator of care: (1)

authority: (2)

I board under another facility's daily care, but retain all decision-making me, but I make all major decisions: (3)

I board at a facility that makes all decisions for me: (4)

Q17 With regard to veterinary decisions: of the animals you personally own for dressage, please enter the number of animals for which the following statements are true:

I am the sole communicator for all veterinary decisions: (1)

I discuss all veterinary decisions with my trainer/manager, but make all ultimate decisions: (2)

I am updated by my trainer/manager or vet regarding all veterinary decisions they have made: (3)

I prefer only to be updated regarding veterinary decisions when I ask: (4) 
Q18 With regard to farrier-related decisions: of the animals you personally own for dressage, please enter the number of animals for which the following statements are true:

I am the sole communicator for all farrier-related decisions: (1) I discuss all farrier-related decisions with my

trainer/manager/veterinarian, but make all ultimate decisions: (2)

I am updated by my trainer/manager/veterinarian or farrier regarding all farrier-related decisions they have made: (3)

I prefer only to be updated regarding farrier-related decisions when I ask:

Q20 You've made it to the last section! Please answer the following three questions as they relate best to your involvement in the equine industry as a whole:

Please select the category best representing your current age:

Under 21 years of age (1)

O 22-35 years of age (2)

O 36-49 years of age (3)

O $50+$ years of age (4)

Q21 Please select the category that best represents the number of years you have been active in the equine industry (any discipline):

O I have never been actively involved in the equine industry (1)

0 -5 years $(2)$

O 6-10 years (3)

O 11-20 years (4)

O 21-40 years (5)

O 41-60 years (6)

Over 60 years (7)

If I have never been actively ... Is Selected, Then Skip To End of Block

Q22 Please select all equine disciplines in which you have regularly participated in the past, competitively or non-competitively.

$\square$ I have not ever been actively involved in an equine discipline (1)

$\square$ Dressage (2)

$\square$ Hunters (3)

$\square$ Jumpers (4)

$\square$ Eventing (5)

P Park Horse/Saddle Seat (21)

$\square$ Reining (6)

- Ranch Horsemanship (7)

- Barrel Racing (20)

口 Gymkhana/Gaming (8)

$\square$ Polo (9)

口 Racing (10)

a Pleasure Horse (11)

口 Breed Shows (12) 
- Competitive Trail/Endurance (13)

Driving (14)

글 Therapeutic Riding (15)

口 Trail Riding (16)

口 Natural Horsemanship (17)

口 Vaulting (18)

Other (19) 
APPENDIX B

Cover Letter 
1 December 2015

\section{Dear 2015 USDF Member:}

As a 2015 member of the United States Dressage Federation, you are key to the development of the American dressage industry. You are a valued representative of a unique population in the United States, and your experiences, perspectives, and talents are incredibly valuable assets to our industry.

I am Dawn Mackenzie, a graduate student in Agricultural and Extension Education; and under the direction of my advisor, Dr. Harry N. Boone, Jr., we are conducting this survey to determine the goals of 2015 USDF members, and the educational opportunities available to them within the United States. The study will also identify obstacles currently faced within the current American dressage environment. The results will be used to prepare a thesis to partially fulfill the requirements for a Masters of Science degree in Agricultural and Extension Education.

We are contacting some members of the United States Dressage Federation who had 2015 Participating, Youth Participating, Group, or Educational Memberships for this study. The results will provide information on educational opportunities and obstacles faced by members that can improve services provided many groups, including regional dressage organizations, collegiate dressage programs, equine Extension programs, and existing training support infrastructure within the USDF. The results will be used to assist in the development of educational programing and support infrastructure for dressage enthusiasts in the United States. Please take a few moments and share your opinions with us.

Participation in this research study is completely voluntary and all information you provide will be held as confidential as possible. The survey should only take about fifteen minutes to complete, and your response to the survey is crucial to the success of the study. You may skip any question you are not comfortable answering and you can stop at any time. Each email received by a 2015 USDF member will have its own individual link to access the survey. This will be used to identify non-respondents for follow-up reminders, not individuals' answers. Survey results will be reported in a summary format and individual responses will not be identifiable.

The Institutional Review Board (IRB) at West Virginia University has approved this study. If you have any questions or concerns about completing the questionnaire or about being in this study, you may contact me at DaMackenzie@mail.wvu.edu or (518) 657.1773 .

Please click the highlighted link below to access the study no later than $\mathbf{3 0}$

December 2015. Thank you in advance for your assistance with this research effort. We sincerely appreciate your participation.

Sincerely, 
APPENDIX C

Credentials Sought For Instructors 
The following comments were recorded directly from the Qualtrics data and no edits were made for grammatical and/or spelling errors.

A persons personal accomplishments in riding, training, judging, and instructing; their actual experience in the real world.

a philosphy I agree with and someone who is kind in their training techniques but follows the classical dressage and can explain in multiple ways to achieve the same outcomes

A show record that is succesful

A true horseman/woman who can also instruct. No certification or training program can determine that. It is determined only through observation.

Ability to actually teach and interact well with people

ability to communicate with me in a way that translates to success with training and moving up through the levels

ability to explain \&quot;how\&quot; to do something rather than what the outcome should be

Ability to help rider improve seat a.d hands with clear instruction

Ability to ride a horse correctly.

Ability to teach

ability to teach (not every great rider can do this)

ability to TEACH!!!!

Ability to teach. A trainer that has horses in her stable from training to GP.

Accomplished in more ways than a few

Accomplishment

Accomplishment of riders under the instructor

accomplishments

Accomplishments

Accomplishments

Accomplishments as a rider herself. Has a complete program.

ACCOMPLISHMENTS DOING IN SHOW RING

Accomplishments of students

accomplishments of the instructor and his/her students

accomplishments of the trainers as a rider, and horses ridden

accomplishments of trainer's students

Active participation in USDF shows \&amp; events

actively competing in community 
Actively showing

Activity Within The Show Community (Licensed)

adherence to true classical training methods, happy horses

Also, look for results in their riding or students

American Association for Horsemanship Safety certification

American Association for Horsemanship Safety certification

amount of competition experience on different horses at all levels (centerline scores record)

amount of experience in showing and level reached

An individual that articulates classic horsemanship principles and $d$ monstrates that they are knowledgable. Also a kind person that helps me focus on my journey.

An instructor who has successfully shown

An instructor who's students do well in the show ring and who shows him/herself

An instructor with expertise in both dressage \&amp; eventing.

An understanding of biomechanics of rider

And the quality of their students and horses meaning are the students learning and happy

And watch a lesson to evaluate

Auditing instructors at clinics or symposiums

Availability

availability in the very rural area where $i$ live

Availability, and if I like what I see when watching others' lessons

Awareness of correct equine and human biomechanics

Background, with whom and how they have trained \&quot; classically \&quot; or not

Based on performance at shows and quality of the rider's seat

Because certifications and medals don't necessarily reflect the competence of an instructor these are nice to have but not a guarantee. You have to try see if the two of you fit in philosophy and goals.

being a judge is an added bonus

Being a USEF official (judge)

Being able to watch the instructor ride and teach

beliefs associated with training

Bereiter F.N and Reitlehrer F.N

Body type similar to mine

British Horse society 
British Horse Society (B.H.S.A.I, B.H.S.I)

British Horse Society (BHSAI or higher)

British Horse Society certification

British Horse Society graduate

British Horse Society Instructors

British horse society or German

British Horse Socity Instructor

By observing, if I like the way they ride and treat the horse then I might be interested in a lesson.

can trainer communicate a thought more than one way.

career and show experience

career credibility in the industry

Center line dressage scores

Centered Riding Instructor

Centered Riding Instructor Level III or above

Centerline now has the Star system.

Centerline rider rating

Centerline Scores

Centerline scores

Centerline Scores

Centerline scores and horses ridden ... did trainer bring horses up or buy already made centerline scores.com

centerlinescores.com

centerlinescores.com --gives idea of breadth of show exp vs just the medals

Certification and past glory does not equate with ability to teach! I observe and research for what they do with variety of horses and riders!

Certification by the school of legerete

Certified by a classical master, e.g. etc.

Certified Centered Riding Instructor Certification

Certified German master from Warendorfe Germany

Certified judge / judging experience, preferably international

Character and demeanor

Classical dressage / SRS instruction/clinics 
Classical Dressage background

Classical dressage background

Classical instructors only.

Classical training

Classically trained from Germany with a license.

Clinic reputation

Clinicians who are local as I don't trailer myself - need someone to take me

clinics

closeness, availability

Closest recommended instructor

Coach to successfull competitors

Coaches I have watched coaching and or riding

Commitement to the system of dressage

Communication skills - ability to explain the steps to improved riding partnerships

Compatibility - do we mesh, and communicate well

Competent riding, style in line with mine

competes and rains in dressage - this area is extremely limited in instructors

competition history

Competition History and Scores

Competition record

Competition record

Competition record

Competition record

competition record and observation at competitions

Competition record of instructor and students

Competition record of instructor is important, i.e. how many horses have they brought up through the levels to FEI.

Competition records/scores/experience

Competition results

competition results

Competition Results of trainer and/or students

Competition results; training results; international experience

Competition success 
Competition success -- both personal and customers

Competition success, communication skills, personality

Competitions and awards the instructor and the instructor's students has won and the

Competitive Record

competitor

Condition of facilities, condition of horses, training style

Correct dressage teaching. More German instruction of correct horses poll. Not forced.

cost

Current \&amp; former studen performance records

Current / active competitor/trainer

Current Showing Scores

currently competing

Currently Riding and Showing

Demonstrated and extraordinary biomechanics understanding

Demonstrated capability

demonstrates good riding technique, knowledgeable and correct instruction

Desire to highlight students success

DID THEY TRAIN THE HORSE THEY COMPETED OR WAS IT REMOTE CONTROL

Direct observation of horsemanship skills

Direct observation of teaching and communication skills, and success of existing team members

Do not participate

does the instructor still actively ride

don't seek help outside of barn

Dressage judges

Dressage judges

Dressage Olympians

dressage scores and levels

Ease of travel i.e. local availability

Educated trainer as coach

Education/certification overseas

effective instructor..positive 
Emphasis on classical dressage

Encouraging to her students no matter what breed of horse or riders personal goals.

European and American

European credentials

European trained

Excellent teaching skills. Ability to communicate clearly

experiance training multiple horses to GP and those horses being sane, healty and happy.

Experience

experience

experience

Experience

Experience

Experience

Experience and previous students

Experience as an instructor

Experience bringing young horses through the levels

experience in training horses and students, plus success of horses and students in shows

Experience in training own horse

Experience training horses and students up the levels

Experience training in Germany/Europe

Experience training their OWN horse through the levels. It's easy enough to earn bronze, silver, gold on someone elses horse. For me, it just doesn't mean very much.

experience with lower level riders

Experience with top trainers/clinicians

experience, espicially show record seeing as how I am interested in showing to the best of my ability

Experience, personality, teaching methods, riding ability

Experience/education/achievements regardless of country of origin

feeling as if I've learned something

FEI

FEI competitive participant

FEI JUDGES AND NOTABLE TRAINERS

FEI judges and trainers who priduce grand prix horses 


\section{FEI Trainer and Competitor}

FEI training \&amp; competition experience with multiple horses + student success

Firm belief in and practice of classical training and rejection of focusing on front end of horse. Philosophy of rewarding promptly when horse tries and not drilling. Focus on improving ability of horse to use it's back and not on competition.

Fit

Fit with my needs and goals.

FN license (bereiter, eg)

German Bereiter

german bereiter(sp)

German Raines (FN)

good riding ability and teaching ability

Good teaching is most important to me. Degrees do not guarantee good teaching practices.

Good teaching personality not too full of themselves.

Grand Prix show record at the High Performance Level or better

Grand Prix training experience

Happiness of customers

Happiness of the horses

Have had success training FEI horses

have never sought dressage instruction

Have they trained horses to Grand Prix as well as showing Grand Prix

Having seen them ride and train at local shows

having seen trainer interact with students and horses at shows or clinics

Having shown/trained a horse up the levels (experience)

Having trained their own horses

having watched person ride

Having watched the instructor ride his/her own horse

Having watched them ride successfully at shows while being good to their horses

high performance experience

High performance riders and trainers

history of bringing riders and horses up the levels

History of success in training horses and in the showing. 
history of success,

History of their accomplishments

Horse show record

Horses developed by instructor $\sim$ fei level

horses trained to FEI level

How her horses look: healthy, cared for

How many FEI horses trainer has trained, and moral ethics.

How successful they are in the show ring

How the horses look and behave w the trainer

how their horses look and go

how their students are doing

How they are with their horses

How they students do

how they train and what their horses look like

how well both the instructor, and the instructor's students perform in shows

how well they ride and how well they teach...I watch them teach first

Humane/classical treatment of the horse

I also watch their lessons to see how he/she interacts with clients and horses

I always watch them teach and ride; a classical base and success with horses is key to me.

I am a show secretary and do not ride.

I am currently competing PSg so want somone at a higher level

I am old and have stopped riding but I am still interested in everything

I am relatively new to dressage and becoming familiar with the accreditation process for trainers. I will begin to look for more \&quot;profession\&quot; certifications in the future. I do try to lesson with certified USEF official judges. \&quot;S\&quot; , \&quot;R\&quot; and \&quot;r\&quot; at this point. Also look for individuals that have had training at the SRS in Vienna or Cade Noir in France.

I am USDF gold medalist, I need someone who can outride me

I audit prior to participating.

I do not participate in this

I do not ride. I choose a trainer for horses based on reputation.

I don't think highly of Collegiate degree or trainer certification programs in the US.

I evaluate on as needed basis. Most don't have a clue so I do almost all my own training. 
I have a main trainer at the barn and take my horse to a lot of I is off site with higher level trainers

I have a trainer with BHS that I've been with for 20 years.

I like an instructor who can supply school master horses. I like an instructor who competes his/her own horses and is actively growing.

I like to observe lessonsâf”'too often instructors can ride but not teach

I like to watch them ride. I also like to watch a lesson and take a lesson. Sometimes it is the only way to get a good match. .

I like training with current judges

I live in Alaska. Trainers are very limited in supply. So you take what you can get into.

I look at their show record and how they teach

I look for a trainer who is currently showing and doing well. Also, this person is personable and gets her point across with respect to the rider and horse

I look for personal experience and teaching ability. Certifications are nice, but not as important as ability

I look for rider accomplishments and experience.

I observe clinics or lessons from instructor first

I observe potential instructor riding and teaching.

I observe the instructor with other riders ad horses first

I prefer instructors who have trained with European instructors.

I prefer to see them ride, then watch how their horses move.

I seek dressage instruction for carriage driving. My instructor is personally recommended. He himself was trained as reitlehrer in Germany.

I seek instructors that have worked with green horses and not merely ridden \&quot;made\&quot; horses to obtain show credentials.

I seek olympians or international riders overseas

I think all credentials are important, especially those geared specifically towards instruction (ARIA, CHA, etc.)

I typically try people out once, or go watch them teach. Then I decide if their instructional methods work for me.

I want them to know more than I do and to be very experienced and good instructors too. I don't care about medals; many bad horsemen get those medals with made horses in a few shows.

I want to see the instructor ride well, train well and compete successfully. I want an instructor who is considerate of the horse and rider. I want an instructor who is honest and hard working. And not over priced. 
I watch how the horse response to the rider, if the horse is happy and comfortable, I will check into the rider

I watch how they ride and I watch how they teach. I choose someone who uses language I understand, someone who is practical, going beyond fancy wording, and who understands the actual meaning of the terms.

I watch other instructors at shows, how they treat their horses and students.

I watch the trainer work with animals and train...I am a certified natural trainer and start my own horses. I do not tolerate \&quot;hard\&quot; loud trainers, or trainers with bad habits...horses heads beyond vertical, neck bending vice poll bending, riding on the fore vice engaging the hind properly. ...

I watch their lessons before deciding. Look for classical traing.

I will audit a lesson.

I work with team coaches or team members

If I feel I benefit from the instruction provided

If I like the person

If I were to look for a trainer to help me with competition, a show record for the instructo would be important.

If their students are scoring well at dressage shows.

If they or their students do well competing

individual's accomplishments (chamionships, show record)

Instructor has students who are competing sucessfully.

Instructor is a respected USEF dressage judge.

Instructor must be successful competitor and USDF member

Instructor riding skill and horsemanship

Instructor that actively participates in furthering their education \&amp; competes, positive, ethical training of the horse \&amp; rider

instructor's and other students' competition and judging accomplishments

instructor's attitude toward horse and rider

Instructor's experience in training, riding, competing and barn management

Instructors I have observed

Instructors philosophy behind training offered

Instructors riding ability and show experience

Instructors success with students and horses trained

Instructors teaching style

instructor's writings 
International dressage credentials

International dressage organizations

International experience, reputation

International FEI participant, over 40 years old with lifelong dressage education

international instructors

International Ranking and experience

International success of rider

International trainers

Interview

Interview with candidate

is he/she just a competitor or an actual horseman

It is also important to me as to how involved they are staying in the Dressage field. How often they teach along with the ability of their riders. Also they are accomplishments. It is also important to me if they were continuing their own education in some manner.

It is difficult to determine a persons credentials when searching for a dressage instructor

Judge credentials

Judge, performance record

judge's license

judges, international riders

judging certification on national or international level

judging credentials

judging dredentials

Judging Experiance

Judging license

Judging program. as the instructor cert. programs not as available or relevant

Kindness to the horse and reliability

Knowledgable and understanding trainer that is not afraid to be honest.

knowledge

Knowledge and experience training and teaching; success of students

Knowledge and training system

Knowledge of general horsemanship; ability to connect with me and with my horse; ability to articulate concepts without the use of jargon; willingness to get on my horse and 'show me.' 
Knowledge that is real not just the talk, been with the same instructor since 1994, been thru 3 horses, working on Grand Prix with third horse. All have started with Training Level

Knowledgeable instructor that has trained horses from Intro to GP and has success in the show ring. Cares for the horse and is innovative with their ideas. Continues their own education and knows how to assess a rider to find what works best for him/her.

known and respected reputation in the region; actually competition record

L program graduate

length of career in relevant experience

Length of time in business

Length of time they have been teaching and what big names they have worked with.

Lessons at a barn which has produced many winners

Level of competition of trainer

Licensed judge

Life experiences

Like to either clinic and/or watch the instructor coach and show to see if they may be a good fit for my horses and I

Local trainer with advanced training and showing experience at all levels including Grand Prix..

local trainer. not many/none certified in Southern Oregon.

locale

Location

location

Location

location close to me

Long term performance proof of ability and traing

Longevity in the discipline, accomplishments by their students and/or horses trained, ability to teach concepts not just ride well, reputation for safe and competent horsemanship, love of dressage and its history and values

Made horses can make medals so while I appreciate medals they're not required for me to respect an instructor.

Manners!

Mass License

match to horse and rider

match to training goals and techniques 